Portland State University

PDXScholar

Civil and Environmental Engineering Faculty

Publications and Presentations

Civil and Environmental Engineering

10-1-1994

\title{
Particle Trapping in Estuarine Tidal Flows
}

David A. Jay

Portland State University

Jeffery D. Musiak

Follow this and additional works at: https://pdxscholar.library.pdx.edu/cengin_fac

Part of the Civil and Environmental Engineering Commons

Let us know how access to this document benefits you.

\section{Citation Details}

Jay, D. A., and J. D. Musiak (1994), Particle trapping in estuarine tidal flows, Journal of Geophysical Research, Vol. 99, No. (C10), p. 20,445-20,461.

This Article is brought to you for free and open access. It has been accepted for inclusion in Civil and Environmental Engineering Faculty Publications and Presentations by an authorized administrator of PDXScholar. Please contact us if we can make this document more accessible: pdxscholar@pdx.edu. 


\title{
Particle trapping in estuarine tidal flows
}

\author{
David A. Jay and Jeffery D. Musiak
}

physics Program, University of Washington, Seattle

Abstract. Particle trapping in estuarine turbidity maxima (ETM) is caused primarily by

convergent mean and/or tidal fluxes of sediment. The result is an approximately bell-shaped

along-channel distribution of vertically integrated, tidal cycle mean suspended sediment

concentration. Observations from the Columbia River estuary suggest that (1) strong two-layer

or internal along-channel residual and overtide flows are generated by time-varying stratification

and (2) correlations between the near-bed velocity and the suspended sediment fields at these

frequencies are important in landward transport of sediment. A new spatially and temporally

integrated form of the sediment conservation equation has been derived to analyze this trapping

process. Time changes in tidally averaged sediment concentration between two estuarine cross

sections can be shown to be related to the divergence of the seaward, river flow transport; the

divergence of velocity shear-sediment stratification correlations for the mean flow and each tidal

constituent; and net erosion or deposition at the bed. Vertically integrated variables other than

seaward river transport are absent from this integrated balance. Analysis of sediment fluxes

using this balance supports the idea that internal residual and overtide circulations are primarily

responsible for the landward sediment transport on the seaward side of ETM found near the

upstream limits of salinity intrusion. The balance also shows that attempts to represent fluxes

causing trapping of sediment in an ETM as a product of a time-mean, vertically integrated,

along-channel gradient and a diffusivity inevitably lead to the appearance of countergradient

transport and thus a negative diffusivity on the seaward side of the ETM. This result occurs

because the trapping process is inherently nonlinear and at least two-dimensional and because a

one-dimensional representation is physically unrealistic.

\section{Introduction}

Trapping of particles by convergent suspended sediment transport often creates pronounced estuarine turbidity maxima (ETM) in river estuaries and narrow tidal channels (Figure 1). This concentration of particles commonly occurs near the upstream limits of salinity intrusion and has been attributed to density-driven residual circulation [Nichols and Poor, 1967; Festa and Hansen, 1978; Dyer, 1988]. Trapping may, however, occur under a variety of circumstances, and a number of internal and barotropic causal mechanisms are catalogued below. The diversity of advective mechanisms that can bring about localized concentration of sediment in ETM indicates a need for a unified methodology with which to analyze sediment fluxes and their influence on ETM sediment concentration. The primary purpose of this paper is, accordingly, to present an integral sediment conservation expression for channelized tidal flows that defines changes in ETM suspended sediment concentration in terms of bed erosion/deposition and fluxes of sediment through boundaries at two along-channel positions. This spatially and temporally integrated

sediment balance includes both horizontal (advection and spatially variable resuspension) and vertical (settling, erosion, and deposition) aspects of ETM suspended sediment behavior for each sediment size class. Nonconservative behavior such as aggregation and biological consumption or production could readily be added; therefore a modified form of this balance might also be used to analyze interactions of the suspended sediment field with biological processes in a realistic advective context.

Copyright 1994 by the American Geophysical Union.

Paper number 94JC00971

0148-0227/94/94JC-00971 $\$ 05.00$
This sediment balance and observations taken in the Columbia River estuary are then used to provide a new explanation of processes leading to particle trapping in an ETM associated with the upstream limits of salinity intrusion. Under this interpretation, ETM formation is caused by convergent shear fluxes in residual and overtide flows that occur at this location. The relevant internal residual and overtide currents are primarily caused by time-varying stratification through a process known as "internal tidal asymmetry" [Jay and Musiak, 1994], though gravitational circulation also contributes at zero frequency. Finally, we explore modeling implications of the fact that estuarine suspended sediment transport is inevitably at least a two-dimensional problem; that is, both horizontal advection and vertical processes (erosion, deposition, settling, and vertical mixing) must be considered. Neither one-dimensional formulations in the vertical, essentially Rouse balances modified to include time variation and stratification nor vertically integrated models that represent tidal transports of sediment as horizontal diffusion can be expected to yield an adequate representation of particle trapping in tidal channels. The former cannot represent advection at all, while the latter can do so only through artificial, countergradient transport. Thus estuaries pose a very different modeling problem from either continental shelves (at least those with smooth topography) or rivers. In the former, horizontal uniformity may normally be assumed, and wind-wave mean flow interactions affect vertical mass and momentum transfer but do not alter the scalar field by horizontal advection [e.g., Kachel and Smith, 1989; Glenn and Grant, 1987]. In the latter, tidal wave fluxes, salinity stratification, and horizontal circulation modes driven by density effects are all absent. Only stratification by the suspended sediment field itself need be considered, and fluvial flows may normally be treated as time invariant. 

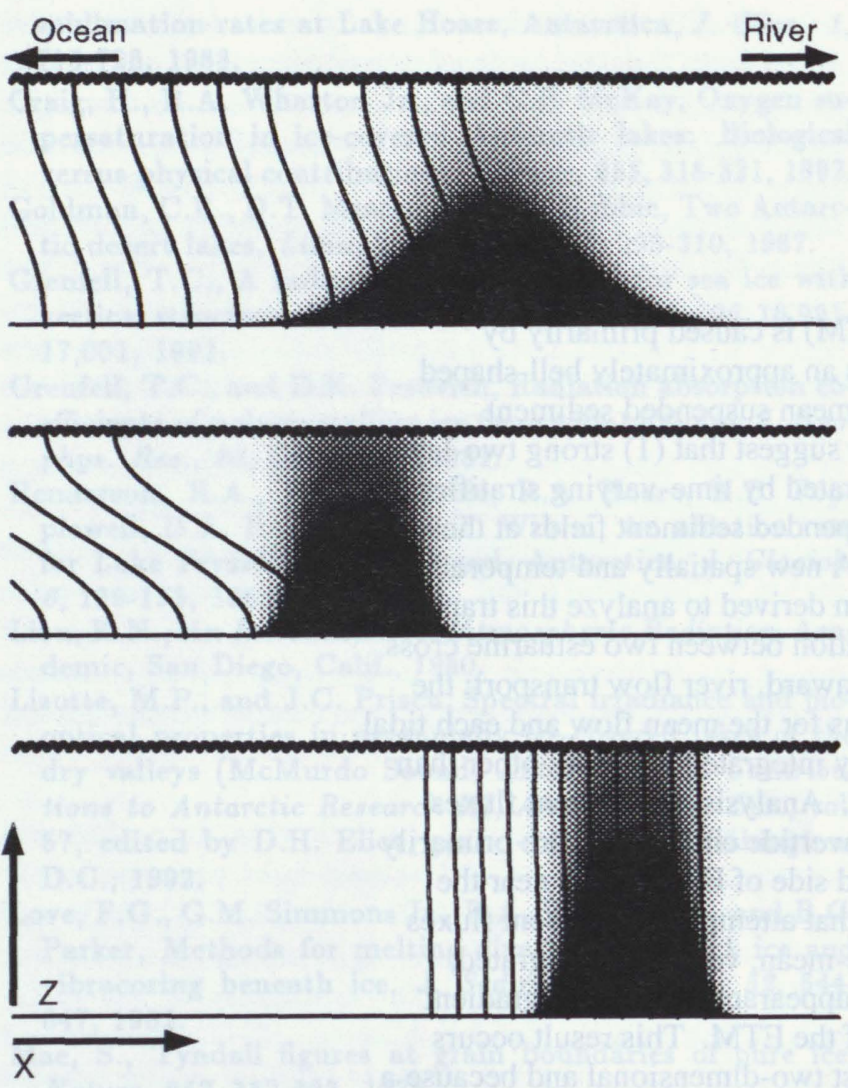

Figure 1. Schematic of (top to bottom) mean, ebb, and flood scalar fields for two-dimensional (in the along-channel and vertical directions) estuarine turbidity maxima (ETM). Contours show the density field, and shading shows sediment concentration; the ocean is to the left, and the river is to the right. Tidal straining of the density field causes stratification to be greater on ebb than flood. The sediment field is affected by both horizontal advection and vertical processes (erosion, deposition, settling, and vertical mixing).

\section{ETM Generation Mechanisms}

The internal tidal asymmetry particle-trapping mechanism discussed below for the Columbia River estuary is found in many river estuaries [Jay and Musiak, 1994]. Nonetheless, this particular transport process is not the only means by which convergent horizontal sediment fluxes may create an ETM. Several other advective ETM generation mechanisms have been proposed, and these cover almost the entire spectrum of estuarine circulation processes. Relevant barotropic processes include tidal residual trapping over a topographic high (theoretical calculations [Ianniello, 1979]), tidally varying fluxes from tidal flats (in the Tay estuary, Scotland [Weir and McManus, 1987]), and barotropic tidal wave steepening (overtide trapping in the Gironde estuary, France [Allen et al., 1980]). Steady, two-layer gravitational circulation has long been known to cause particle trapping [e.g., Nichols and Poor, 1967]. Hamblin [1989] and Geyer [1993] have emphasized an effect of stratification different from internal tidal asymmetry. Inhibition of vertical mixing by stratification decreases the upward flux associated with vertical mixing relative to the downward (settling) flux of sediment in a way that may be correlated with horizontal advection. Several mechanisms may, moreover, be active in causing a single ETM. For example, during low-flow conditions in North San Francisco
Bay, an ETM trapped just seaward of a topographic high [Meade, 1972] appears to be maintained by a combination of tidal residual and gravitational circulation interacting with topography. Finally, multiple ETM may occur in one system. Three simultaneous ETM have been observed in the Columbia River estuary. The two landward ETM are located near the upstream limits of salinity intrusion in the two main channels and are primarily maintained by internal tidal asymmetry. The more seaward of these ETM may be associated with topographic convergence, but this hypothesis has not been tested.

Other factors in addition to convergent suspended sediment transport may also be important in ETM formation. Trapping in some systems is significantly enhanced by particle aggregation (e.g., Rotterdam Waterway and the Savannah River Estuary [van Leussen, 1988; Krone, 1972]); its occurrence on tidal time scales in other systems remains in doubt (e.g., San Francisco Bay; [Kineke and Sternberg, 1989; Kranck and Milligan, 1992]). Postma [1961], Dyer [1988], and Dyer and Evans [1989] have stressed the role of nonlinearities in deposition and erosion in ETM creation. Nonetheless, numerical models [e.g., Festa and Hansen, 1978] show that particle interaction and bed nonlinearities are not necessary to particle trapping and that the locus of particle concentration (e.g., upstream limits of salinity intrusion or a topographic feature) is determined primarily by advective processes. Fluvial sediment usually makes up the bulk of material in an ETM, but the trapping process is relatively independent of source. Fluxes of material from the river, ocean, or sources in lateral embayment may all play a role [Festa and Hansen, 1978, Weir and McManus, 1987]. The primary importance of the source lies, however, in the quality of the material supplied; it must have a settling velocity matched to the advection processes in the system. If the material supplied is too fine, it will move through the estuary as vertically uniform wash load. If it is too coarse, it will move only as bed load. In neither case can an ETM form.

\section{Formulations of ETM Sediment Transport}

Two factors, the variety of processes causing particle trapping and the inherently Lagrangian nature of particle transport, suggest the use of a wave flux approach in the analysis of ETM. This methodology relates wave transport of wave period variations in a scalar property (sediment concentration in this case) to Stokes drift transport of the mean field [Andrews and McIntyre, 1976, 1978]. In the atmospheric literature it has been used to derive a variety of "nonacceleration" theorems for steady wave fields [Dunkerton, 1980]. In atmospheric nonaccelerated flows in which mixing of the scalar property may be neglected, transport by wave fluxes (i.e., by the Stokes drift) is exactly compensated for by residual flow transport, so that total Lagrangian transport is zero and the scalar field is steady. With modifications to account for vertical mixing and settling, an ETM may be treated in a similar manner.

Most existing models of sediment transport are not based on wave flux concepts and, because of the difficulties inherent in a full three-dimensional calculation of sediment transport, are either one-dimensional in the vertical or vertically integrated (two-dimensional in the horizontal). Wave flux ideas are useful for the light they shed on these conventional models. Onedimensional vertical profiles (Rouse models and the like) traditionally used in analyses of the suspended sediment field have serious defects for representation of the estuarine suspended sediment distribution. They can explain only one aspect of the 
influence of tidally varying stratification, namely, its reduction of vertical suspended sediment mixing relative to settling. Neither the vital, sometimes dominant influence of horizontal mean and wave advection on the vertical distribution of suspended sediment nor the modifying effect of stratification on this alongchannel transport can be considered in such a model.

The analysis that follows will show that vertically integrated models (in one or two horizontal dimensions) typically require a negative horizontal diffusivity to represent an estuarine ETM. The reason for this apparently countergradient transport is as follows. A curve representing vertically averaged sediment concentration in an ETM is approximately bell shaped in the along-channel direction. In the absence of a local source of sediment, this along-channel distribution can be created only by convergent mean and/or wave fluxes. These mean and wave fluxes are typically parameterized in vertically integrated models by a horizontal diffusivity times a horizontal gradient of a vertically averaged sediment concentration. This representation may be called a vertically integrated horizontal diffusion (VIHD) model. As shown in the analysis that follows, ETM formation requires that wave and/or mean fluxes of suspended sediment be upgradient on the seaward side of the ETM, implying a negative horizontal diffusivity in a VIHD model. For the same location, horizontal diffusivities calculated from the monotonic salinity distribution would be uniformly positive. The very different behaviors of salt and sediment stem from the fact that scalar transport in stratified tidal channel flows is inherently at least two-dimensional in the along-channel $(x)$ and vertical $(z)$ directions; that is, maintenance of a scalar balance against fluvial export requires correlations between shear and stratification in the various mean and wave modes. Thus there are fundamental differences between salt and suspended sediment transport that cannot easily be represented in VIHD models, whether in one or two horizontal dimensions. VIHD treatments of suspended sediment transport may give unphysical results, because these treatments incorrectly represent the processes that maintain the suspended sediment balance. It will be shown below, moreover, that even the apparent success of one-dimensional VIHD representations of the salt balance is largely fortuitous and not a result of dynamical similitude. Salt and suspended sediment are by no means exceptional in the difficulties they present for onedimensional models. A dependence on the details of correlations between shear and stratification is a general property of scalar transport in channel flows. Thus correct representation of the shear fluxes that bring about this transport is vital, and two scalars will have the same estuarine transport properties only if they have similar spatial distributions at all relevant wave frequencies.

\section{Representation of Scalar Wave Fluxes}

One possible resolution to the difficulties with the VIHD models discussed in previous paragraphs would be not to integrate vertically. Net vector transport by wave fluxes of a hondiffusive scalar at a single point in the interior of the atmosphere or ocean may be related to a Stokes transport of the mean scalar field. This flux may be parameterized by a product of a local mean gradient times a skew tensor diffusivity that is orthogonal to the mean gradient [Middleton and Loder, 1989]. Such a representation is inappropriate in estuaries because of the dominant importance of vertical mixing and, for particles, settling.

Estuarine transport studies require a different approach. Vertical integration is needed to allow a tractable overall balance, but effects of velocity shear and scalar stratification must be correctly represented. An earlier wave flux analysis of estuarine salt transport [Jay, 1991b] is here generalized. The previous analysis considered only dissolved scalars that, like salt, have a monotonic distribution in the along-channel direction. The present analysis expresses the change in tidal cycle mean sediment concentration between two cross sections (chosen to encompass the ETM) as a sum of three terms. They are the seaward transport by river flow, the along-channel divergence of shear stratification fluxes at mean and wave (tidal) frequencies, and fluxes to and from the bed. The sediment may originate in the ocean, the river, or both. As in the previous treatment, vertically integrated quantities, aside from the seaward river flow transport, are absent in the final result. All wave fluxes are expressed as correlations of shear and sediment stratification in each wave mode.

The theoretical development that follows employs ideas from two wave flux formalisms. The first of these is restricted to small-amplitude waves [Middleton and Loder, 1989] and is sometimes referred to as an "Eulerian" or "weakly nonlinear" theory. Some of the theorems utilized below are, however, more readily proven using a generalized Lagrangian mean (GLM) theory of wave mean flow interaction that covers even unsteady, finite-amplitude waves [Andrews and McIntyre, 1978]. The results employed herein are special cases for steady smallamplitude waves [Dunkerton, 1981]. Unlike most treatments in the atmospheric literature, vertical integration allows inclusion of vertical turbulent fluxes so long as these fluxes are specified at the sea bed and free surface. It is also necessary that the estuary be narrow: less than the smaller of a tidal excursion and the internal Rossby radius. In a wide system with complex topography, certain assumptions concerning the Stokes drift made in both wave flux methodologies employed here are not valid, because strong horizontal gradients in tidal velocity can cause a series representation of the Stokes drift to be nonconvergent [Zimmerman, 1980]; this problem is absent in narrow systems.

Correlations between stratification and shear at mean and wave frequencies replace in the present model the horizontal diffusivities employed in traditional VIHD models. These correlations are substance or size-class specific, so that, for example, a vertically integrated box model is not a property of the flow but of a particular scalar in a flow. This leads to the sensible result that different size classes of sediment have different residence times in an ETM. Similarly, dissolved substances originating in fresh water will have different flux properties and estuarine residence times than those originating in oceanic water masses. These statements are both corollaries of an important general principle: formulation of a meaningful vertically integrated model of scalar transport in a stratified channel flow requires information concerning the vertical distribution of the scalar to be modeled.

\section{Observations of Internal Tidal Asymmetry and Wave Fluxes in the Columbia River Estuary}

A cross-sectionally integrated conservation equation for individual size classes of suspended sediment is derived in the following section. This balance shows that net transport of a scalar quantity through a cross section is related to correlations of velocity shear and the scalar stratification in the mean flow and in each of the various wave modes. A frequency must be prominent 
in both the velocity and scalar fields if it is to contribute to the scalar transport balance. Conversely, if it is prominent in both, it will contribute to the scalar balance unless stratification and shear are exactly $90^{\circ}$ out of phase. Interactions between neighboring frequencies within a tidal species can cause neap-spring variations in residual suspended sediment concentration but cannot contribute at zero frequency. The frequencies that are actually present in the velocity and sediment fields are thus a key issue in understanding suspended sediment transport in tidal channel flows.

Numerous calculations of cross-sectional averaged balances of salinity, sediment and other substances have been carried out in estuaries, as reviewed by Dyer [1973], Fischer [1972] and Jay [1991b]. Several studies have found wave fluxes to play a major role in cross-sectional scalar balances [e.g., Hansen, 1965; Hughes and Rattray, 1980; Dyer, 1978; Lewis and Lewis, 1983; Winterwerp, 1983; Uncles et al., 1985; Jay and Smith, 1990]. These fluxes were invariably assumed to be at the dominant tidal frequency. No available estuarine scalar transport calculation from data has separated all the relevant tidal species, let alone the tidal constituents thereof. Robe's [1968] study was exceptional in having resolved two tidal constituents of the salinity field, the semidiurnal $M_{2}$ and the diurnal $K_{1}$. The complexity of traditional transport expansions has precluded inclusion of additional species and constituents, including overtides. Previous research has not, therefore, resolved the frequency structure of the suspended sediment field in even a preliminary way.

\section{Definitions and Mechanisms}

Observations in the Columbia River estuary suggest that residual and overtide variations in sediment concentration should be large in response to maxima in shear stress on both flood and ebb (Figures 2, 3a, and 3b). This situation is probably typical of estuaries in which the tidal flow is the dominant cause of bed stress. It has long been known that the zero-frequency part of the suspended sediment field combines with two-layer mean gravitational circulation to contribute to ETM formation [Dyer,
1978; Festa and Hansen, 1978]. The relevant questions are (1) whether there is a mechanism to create substantial overtide currents within one salinity intrusion length of the mouth of river estuaries and (2) whether gravitational circulation is the primary or only internal mechanism active in the residual flow frequency band. Barotropic mechanisms can generate substantial overtide currents in the more landward parts of river estuaries, but our observations suggest that a two-layer (internal) mechanism related to salinity intrusion is likely to be a much larger factor in the lower reaches of such systems and thus to be important in ETM formation. This "internal tidal asymmetry" generates both residual and overtide currents and is caused by an interaction between tidal straining of the density field (which drives large changes in vertical turbulent momentum flux) and tidal variations in vertical shear [Jay, 1991a; Jay and Musiak, 1994]. Internal asymmetry thus contributes to ETM maintenance through both the zero-frequency and the overtide parts of the sediment balance.

The mechanism of internal tidal asymmetry can be explained as follows. Consider circulation processes associated with a single tidal frequency (as measured from the surface elevation $\zeta$ and sectionally integrated transport $Q$ ) in a hypothetical narrow estuary having a strong horizontal density gradient. Because of tidal straining of the density field (Figure 1) and the effects thereof on vertical mixing, flood currents are either bottom intensified or nearly uniform in the vertical. Ebb currents are strongly sheared, with a pronounced surface maximum (Figure 4). A Fourier decomposition of the time-varying velocity field yields, in addition to the dominant tidal $M_{2}$ component, internal $Z_{0}$ (zero-frequency), $M_{4}$ and $M_{8}$ flows of about $0.63 \delta$, $0.42 \delta$, and $0.08 \delta$, respectively, where the internal asymmetry $\delta$ is defined in Figure 4 [Jay, 1991a]. Here $\delta$ and therefore all internal modes must integrate to zero over depth in our hypothetical system to satisfy continuity; only $M_{2}$ is found in $\zeta$ and $Q$. Thus the zero-frequency internal mode exhibits a change in sign with depth, and internal overtides show a $180^{\circ}$ phase shift over the depth of the flow. Other internal overtides in addition to $M_{4}$ and $M_{8}$ may appear if maximum and minimum stratification do not occur exactly half a tidal cycle apart, and current meter

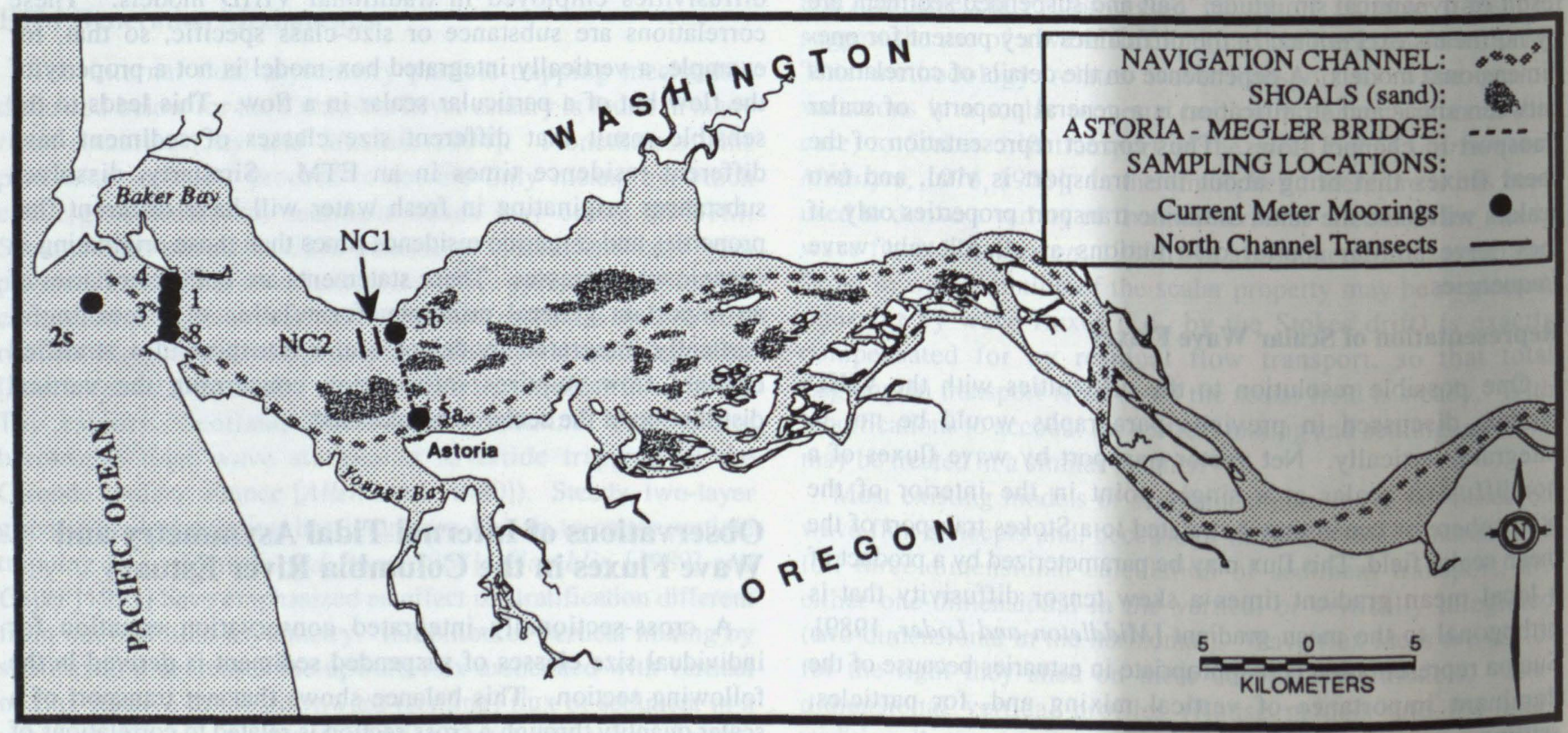

Figure 2. Location map showing sampling stations in the Columbia River estuary and approximate ETM positions. 

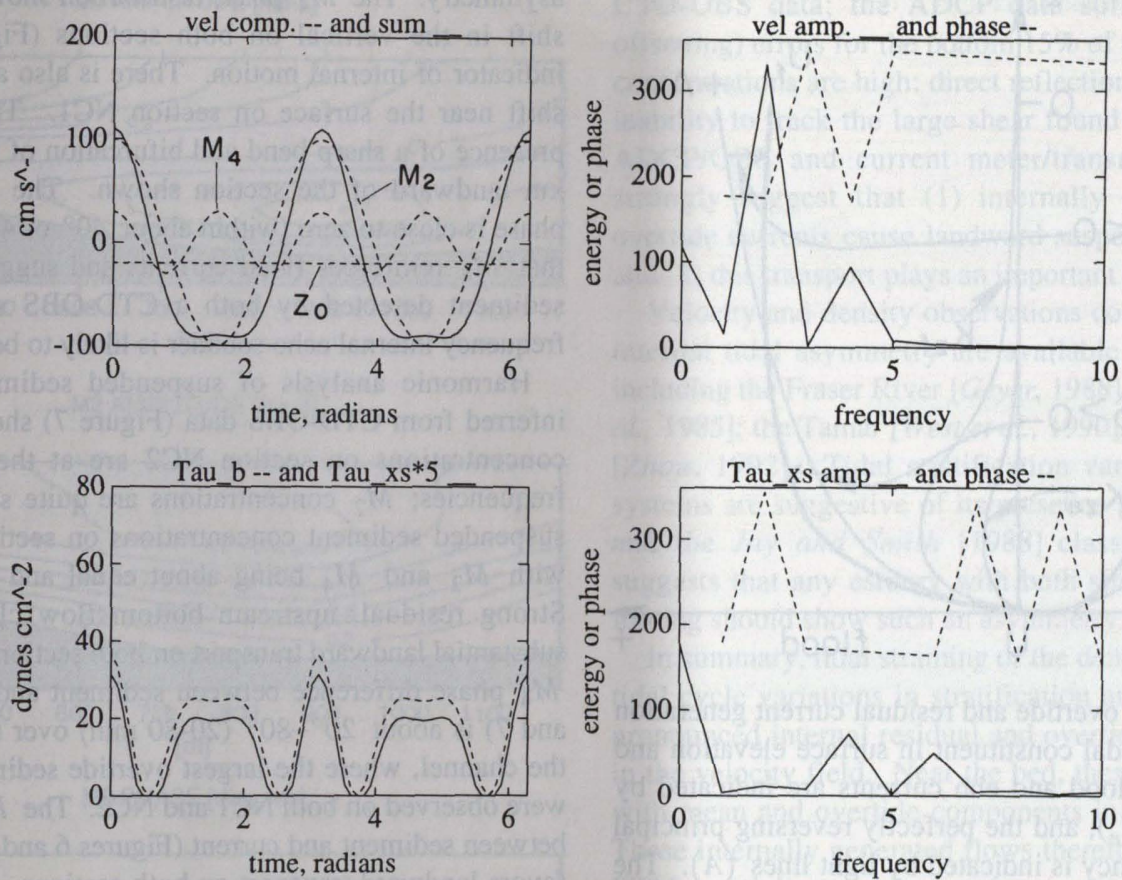

Figure 3a (top left). Time series of near-bed $M_{2}$ (the largest tidal constituent), $M_{4}$ (its first overtide), and residual velocity $\left(Z_{0}\right)$ and total near-bed along-channel velocity; (top right); total velocity amplitude and phase spectra; (lower left); time series of bed stress $T_{b}$ and excess shear stress $T_{x s}$ (assuming a critical shear stress of 8 dyn $\mathrm{cm}^{-2}$ ); (lower right) amplitude and phase spectra for excess shear stress. In this artificial but typical example, $M_{2}$ is almost absent in the $T_{x s}$ spectrum despite being the largest tidal constituent, while the $Z_{0}, M_{4}$, and $M_{6}$ components are prominent. Time on the $x$ axis is in radians for $K_{1}$.
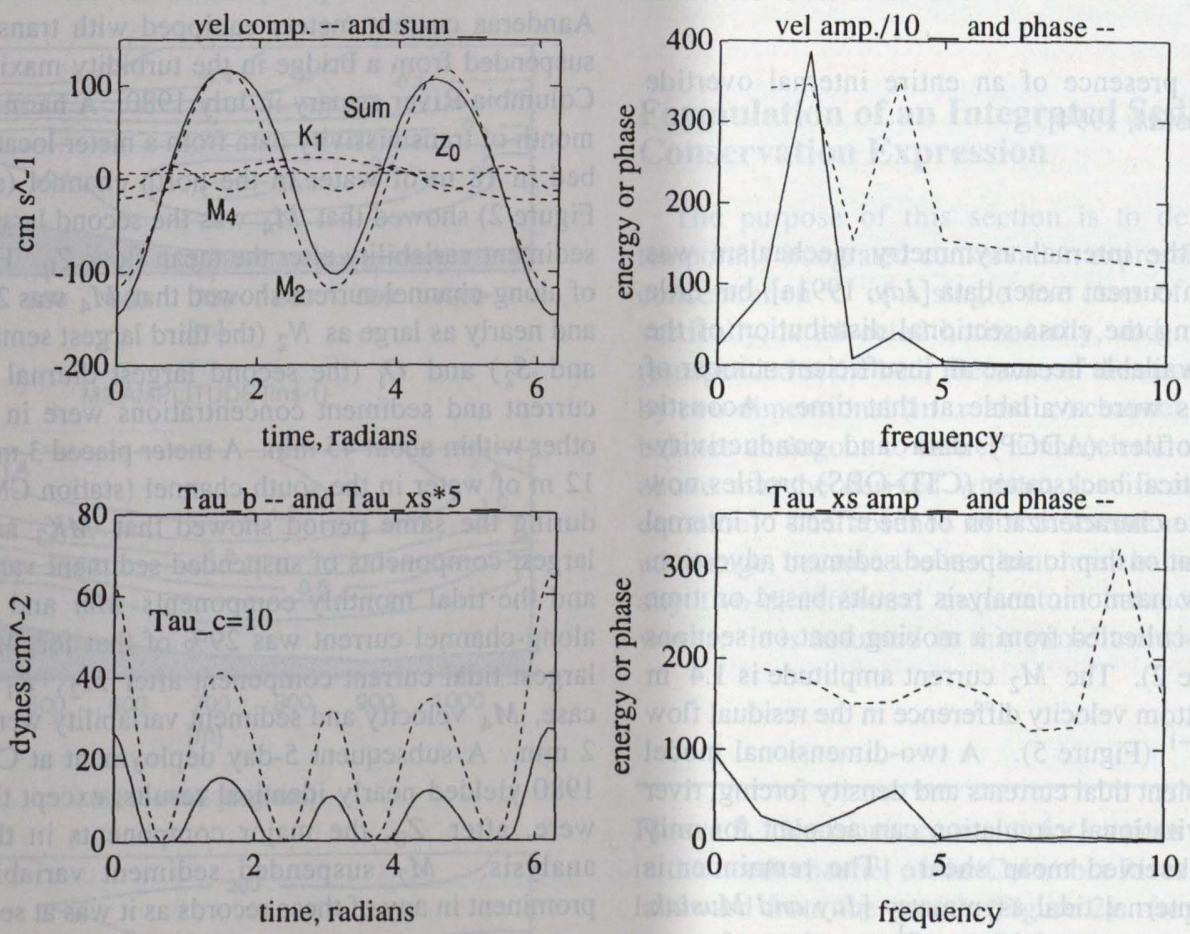

Figure 3b. As in Figure 3a but based on harmonic analyses of data from a current meter $3 \mathrm{~m}$ above the bed near the mouth of the Columbia River estuary (station $2 \mathrm{~S}$ in Figure 2); $K_{1}$ is also included. Again, $M_{2}$ is not a major component in the $T_{x s}$ spectrum, despite its prominence in the current spectrum. 


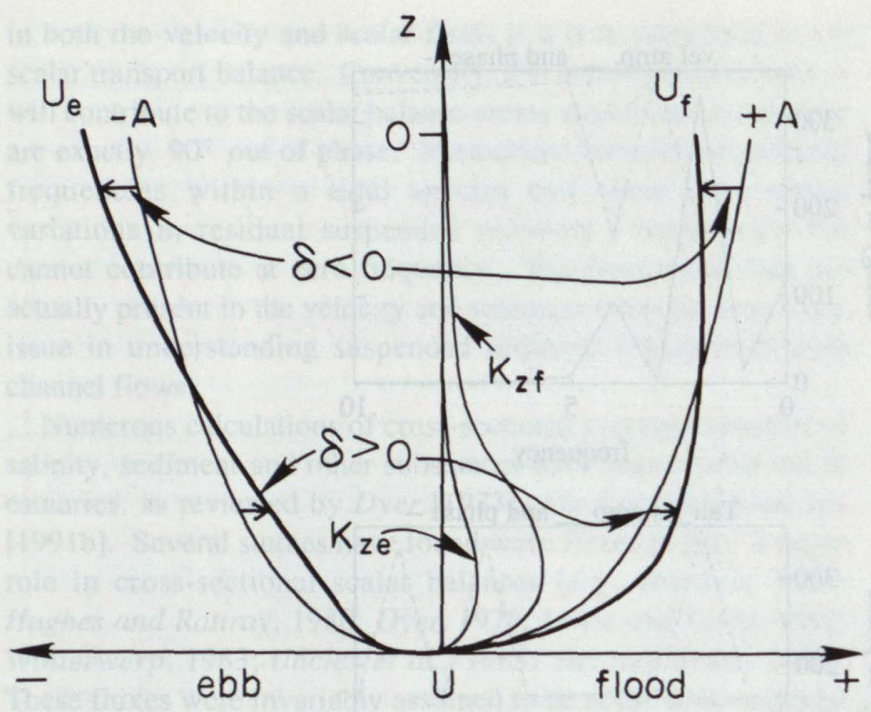

Figure 4. Schematic of overtide and residual current generation by a single barotropic tidal constituent in surface elevation and transport. The actual flood and ebb currents are indicated by heavy lines $\left(U_{f}\right.$ and $U_{e}$ ), and the perfectly reversing principal harmonic at tidal frequency is indicated by light lines $(A)$. The presence of a horizontal density gradient and tidal straining of the density field combine to cause flood currents to be vertically rather uniform or bottom intensified. Suppression of vertical mixing causes ebb currents to be surface intensified, as suggested by the profiles of vertical eddy diffusivity $K_{z f}$ and $K_{z e}$. The result is an ebb flood internal asymmetry (represented by $\delta$ ) that integrates to zero, so that it is absent in the vertically integrated flow. A simple Fourier analysis shows that $\delta$ contributes to the motion at zero frequency and to odd overtides $\left(M_{4}, M_{8} \ldots\right)$.

records indicate the presence of an entire internal overtide spectrum [Jay and Musiak, 1994].

\section{Observations}

The existence of the internal asymmetry mechanism was deduced initially from current meter data [Jay, 1991a], but little information concerning the cross-sectional distribution of the internal modes was available because an insufficient number of current meter records were available at that time. Acoustic Doppler current profiler (ADCP) data and conductivitytemperature-depth-optical backscatter (CTD-OBS) profiles now allow a more complete characterization of the effects of internal asymmetry and its relationship to suspended sediment advection. Figures 5 and 6 show harmonic analysis results based on time series of ADCP data collected from a moving boat on sections $\mathrm{NC} 1$ and NC2 (Figure 2). The $M_{2}$ current amplitude is $1.4 \mathrm{~m}$ $\mathrm{s}^{-1}$ and the top-to-bottom velocity difference in the residual flow $Z_{0}$ is about $1 \mathrm{~m} \mathrm{~s}^{-1}$ (Figure 5). A two-dimensional model shows that, given ambient tidal currents and density forcing, river flow and steady gravitational circulation can account for only about $40 \%$ of the observed mean shear. The remainder is associated with the internal tidal asymmetry [Jay and Musiak, 1994]. The $M_{4}$ current reaches $0.25 \mathrm{~m} \mathrm{~s}^{-1}$ near the surface on section $\mathrm{NCl}$ and $0.4 \mathrm{~m} \mathrm{~s}^{-1}$ on $\mathrm{NC2}$. Maximum near-bed $M_{4}$ currents are $0.10 \mathrm{~m} \mathrm{~s}^{-1}$ and $0.2 \mathrm{~m} \mathrm{~s}^{-1}$ on $\mathrm{NC1}$ and $\mathrm{NC2}$, respectively. These $M_{4}$ currents are an order of magnitude larger than those associated with barotropic forcing in this part of the Columbia River estuary and can be generated only by internal asymmetry. The $M_{4}$ phase distribution shows a middepth $180^{\circ}$ shift in the vertical on both sections (Figure 6), a definite indicator of internal motion. There is also a lateral $180^{\circ}$ phase shift near the surface on section NC1. This may reflect the presence of a sharp bend and bifurcation of the channel about 1 $\mathrm{km}$ landward of the section shown. The $2 M_{2}-M_{4}$ relative phase is close to zero (within about $40^{\circ}$ or $40 \mathrm{~min}$ ). This means that $M_{4}$ reinforces flood currents and suggests that suspended sediment detected by both a CTD-OBS sensor and a highfrequency internal echo sounder is likely to be moved landward.

Harmonic analysis of suspended sediment concentrations inferred from CTD-OBS data (Figure 7) shows that the largest concentrations on section NC2 are at the $Z_{0}$ and the $M_{4}$ frequencies; $M_{2}$ concentrations are quite small. The greatest suspended sediment concentrations on section $\mathrm{NC1}$ are at $Z_{0}$, with $M_{2}$ and $M_{4}$ being about equal and somewhat smaller. Strong residual, upstream bottom flow clearly brings about substantial landward transport on both sections. Furthermore, the $M_{4}$ phase difference between sediment and current (Figures 6 and 7 ) is about $20^{\circ}-80^{\circ}(20-80 \mathrm{~min})$ over the northern half of the channel, where the largest overtide sediment concentrations were observed on both $\mathrm{NC} 1$ and NC2. The $M_{2}$ phase difference between sediment and current (Figures 6 and 7) is also small and favors landward transport on both sections. $M_{2}$ concentrations are sufficiently small on section NC2 that $M_{2}$ probably does not play a major role in landward sediment transport, whereas it may actually be the largest contributor to such transport on section $\mathrm{NC} 1$. Thus the ADCP and OBS results together strongly suggest that the residual and $M_{4}$ internal modes bring about landward suspended-sediment transport; $M_{2}$ may also play an important role in some cases.

Further information concerning suspended sediment transport by internal overtides can be obtained from two near-bed Aanderaa current meters equipped with transmissometers and suspended from a bridge in the turbidity maximum zone of the Columbia River estuary in July 1980. A harmonic analysis of 1 month of transmissivity data from a meter located $3 \mathrm{~m}$ above the bed in $18 \mathrm{~m}$ of water in the north channel (station CM-5b in Figure 2) showed that $M_{4}$ was the second largest component of sediment variability after the mean flow $Z_{0}$. Harmonic analysis of along-channel current showed that $M_{4}$ was $20 \%$ as big as $M_{2}$ and nearly as large as $N_{2}$ (the third largest semidiurnal after $M_{2}$ and $S_{2}$ ) and $O_{1}$ (the second largest diurnal after $K_{1}$ ). $M_{4}$ current and sediment concentrations were in phase with each other within about $45 \mathrm{~min}$. A meter placed $3 \mathrm{~m}$ above the bed in $12 \mathrm{~m}$ of water in the south channel (station CM-5a in Figure 1) during the same period showed that $M K_{3}$ and $M_{4}$ were the largest components of suspended sediment variability after $Z_{0}$ and the tidal monthly components $M m$ and $M S f$. The $M_{4}$ along-channel current was $29 \%$ of that for $M_{2}$, making it the largest tidal current component after $M_{2}, K_{1}$ and $S_{2}$. In this case, $M_{4}$ velocity and sediment variability were in phase within $2 \mathrm{~min}$. A subsequent 5-day deployment at CM-5a in October 1980 yielded nearly identical results, except that $M_{4}$ and $M_{2}$ were, after $Z_{0}$, the major components in the transmissivity analysis. $\quad M_{2}$ suspended sediment variability was not as prominent in any of these records as it was at section $\mathrm{NC1}$.

These current meter/transmissivity results cannot be translated directly into sediment transport for a number of reasons, including lack of detailed current meter profiles, uncertainty regarding the transmissivity-sediment concentration relationship, and possible distorting effects of the bridge on the flow. Nor can suspended sediment transport be calculated from the ADCP and 

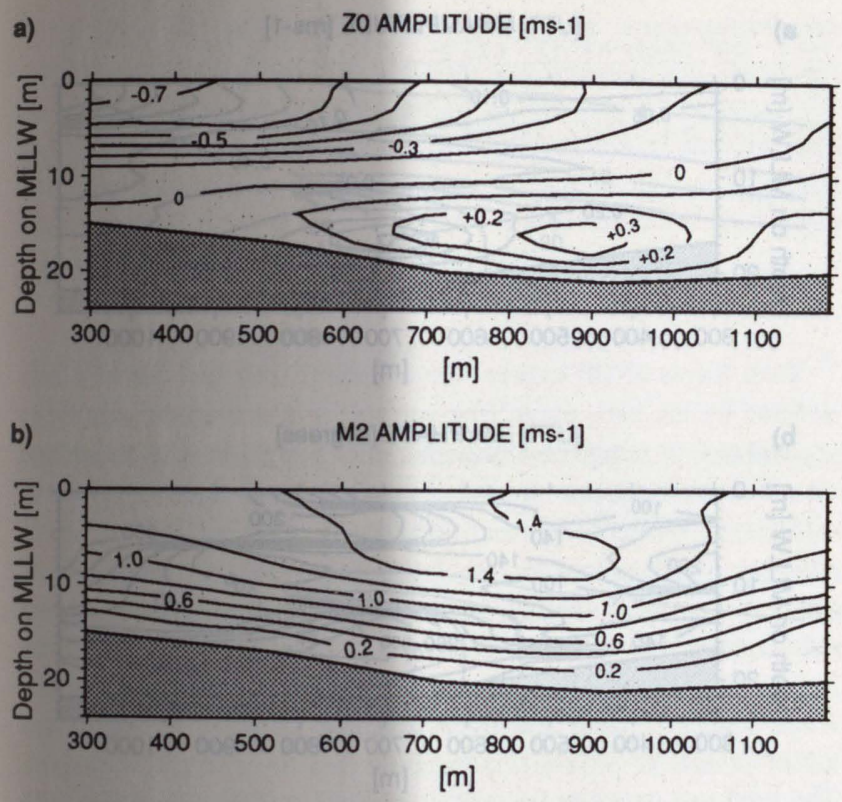

c)

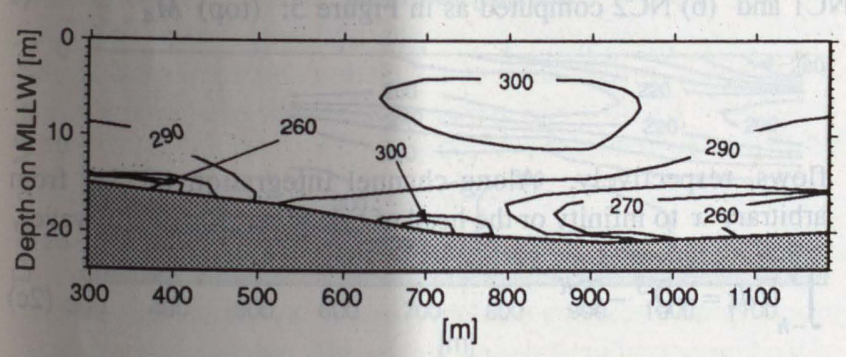

a)

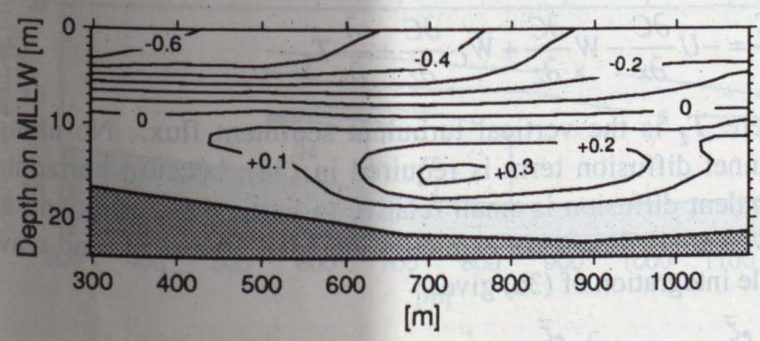

b)

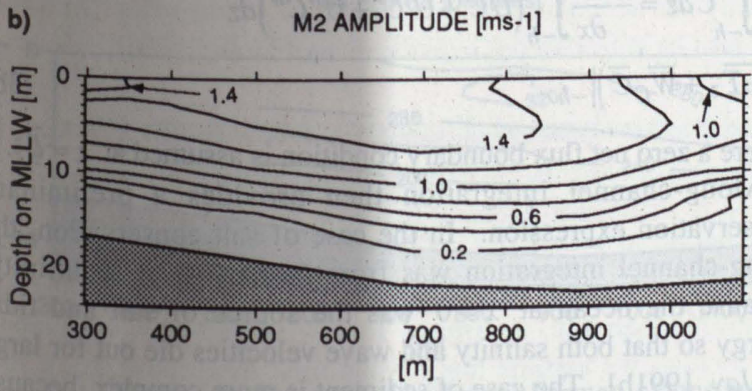

c)

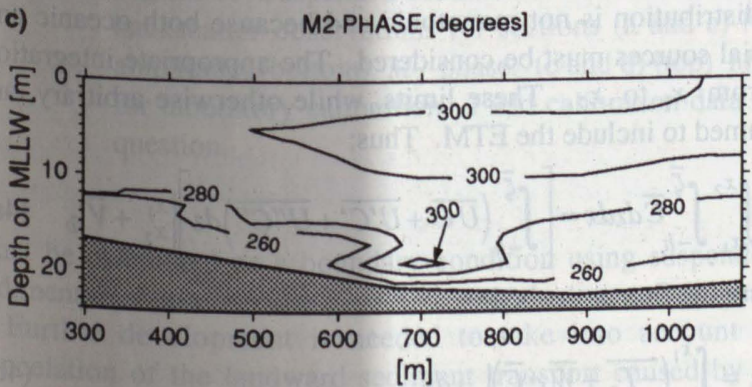

CTD-OBS data; the ADCP data suffer from two (partially offsetting) errors for the bottom $15 \%$ of the flow, where sediment concentrations are high: direct reflection from the bottom and an inability to track the large shear found there. Nonetheless, the $\mathrm{ADCP} / \mathrm{OBS}$ and current meter/transmissivity data together strongly suggest that (1) internally generated residual and overtide currents cause landward suspended sediment transport and (2) this transport plays an important role in ETM generation.

Velocity and density observations confirming the presence of internal tidal asymmetry are available from a dozen estuaries including the Fraser River [Geyer, 1988], the Great Ouse [West et al., 1985]; the Tamar [West et al., 1990], and the Hudson Estuary [Zhou, 1992]. Tidal stratification variations in another eight systems are suggestive of its presence [Jay and Musiak, 1994], and the Jay and Smith [1988] classification system further suggests that any estuary with both strong river flow and tidal forcing should show such an asymmetry.

In summary, tidal straining of the density field and consequent tidal cycle variations in stratification and vertical mixing cause pronounced internal residual and overtide flow modes to appear in the velocity field. Near the bed, these currents are correlated with mean and overtide components in sediment concentration. These internally generated flows therefore, play a strong role in ETM particle trapping and estuarine suspended sediment transport in general. The available observations are, however, too limited to assess spatial and neap-spring variability of ETM flux mechanisms. The substantial diurnal tidal signal in West Coast estuaries certainly introduces substantial semidiurnal variability in bed stress in these systems. This in turn should introduce a substantial semidiurnal sediment shear flux. It seems likely that this semidiurnal flux is absent in East Coast estuaries where diurnal tidal forcing is weak, but this will have to be confirmed from observations.

\section{Formulation of an Integrated Sediment Conservation Expression}

The purpose of this section is to define a spatially and temporally integrated conservation expression for the volumetric concentration $C$ of a single size class of sediment that settles vertically, is advected horizontally, and may be deposited and resuspended at the bed. Because of the strong constraint imposed by two-dimensional (in $x$ and $z$ ) channel geometry, a sediment balance analogous to earlier nonacceleration theorems discussed above may be derived without specification of a momentum equation. The absence of a momentum equation may be an advantage, because the resultant mass balance may be used with any two-dimensional momentum balance that yields steady waves. It is assumed in this two-dimensional analysis that the

Figure 5. Harmonic constants for sections (a) $\mathrm{NC} 1$ and (b) $\mathrm{NC} 2$ in the north channel of the Columbia River estuary about $18 \mathrm{~km}$ landward from the mouth (Figure 2): (top) $Z_{0}$; (middle) $M_{2}$ amplitude; (bottom) $M_{2}$ phase. These were calculated from 30 hours of acoustic Doppler current profiler observations collected by a moving boat and represent about 75 passes across the section, which is plotted looking landward. MLLW, is the mean of the lower low waters occurring each tidal day over a 19 year period. 
a)

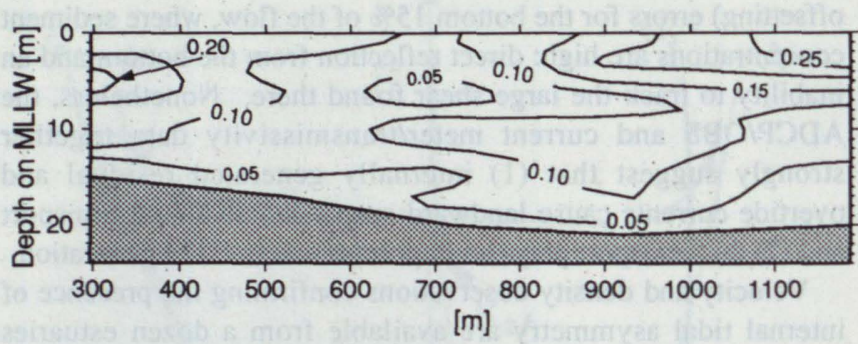

b)

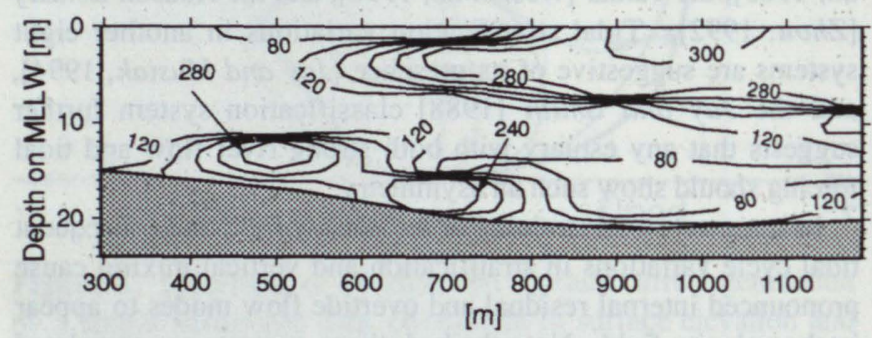

a)

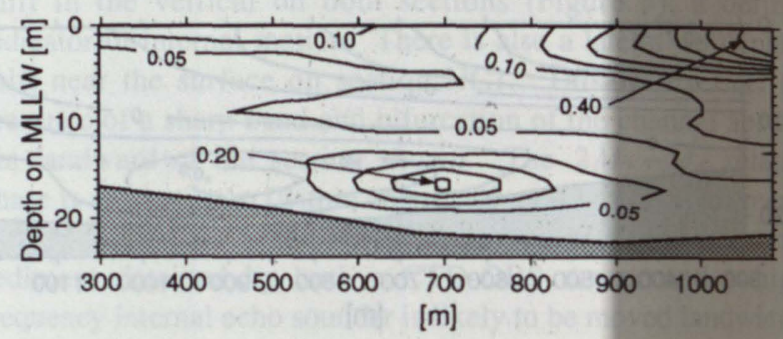

b)

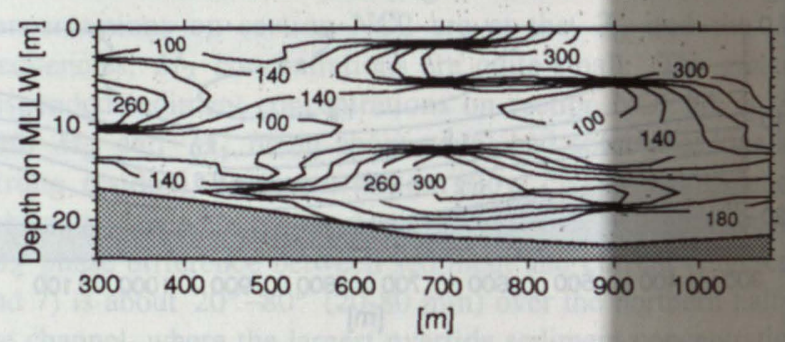

Figure 6. Further harmonic constants for sections (a) NC1 and (b) NC2 computed as in Figure 5: (top) $M_{4}$ amplitude; (bottom) $M_{4}$ phase.

sediment velocity vector $\boldsymbol{U}_{\boldsymbol{C}}=\boldsymbol{U}-\bar{W}_{C}$ differs from that of water $\boldsymbol{U}$ only by a vertical settling velocity $-\bar{W}_{C}$ that is a function of size class but is independent of time and spatial position for each size class. Further, $x$ is positive landward from the ocean, and $z$ is measured upward with $z=0$ at the mean free surface. Each tidal constituent is assumed to be steady and of small amplitude; that is, the ratio of amplitude $\zeta$ to mean depth $H$ is in every case much less than 1 . The sediment concentration is taken as small so that the concentration of water $1-C \approx 1$ everywhere in the interior of the fluid. For simplicity, only one main tidal constituent with one overtide will be considered; generalization to multiple size classes and diurnal and semidiurnal constituents is straightforward. Finally, river flow is assumed to enter only at the landward end of the system. The derivation is similar to that discussed in detail by Jay [1991b] for conservation of salt.

The analysis begins with the assumption that the velocity and sediment concentrations are the sum of wave cycle mean, tide, and overtide contributions:

$$
U=\bar{U}+U^{\prime}+U^{\prime \prime} \quad C=\bar{C}+C^{\prime}+C^{\prime \prime}
$$

where the overbar indicates a wave cycle average, the single prime indicates a tidal variable, and the double prime indicates an overtide variable. All wave variables have zero time mean. Zero-frequency integral conservation of water is expressed by

$\frac{\partial}{\partial x} \int_{-h}^{\bar{\zeta}} \bar{U} d z+\frac{\partial}{\partial x} \int_{-h}^{\bar{\zeta}} \bar{U} s d z+\frac{\partial \bar{\zeta}}{\partial t}=0$

where $-h$ is the bed elevation, total mean depth $H=h+\bar{\zeta}, t$ is time, and the lowest-order approximation to the integral Stokes drift $\bar{Q} S$ is made up of tidal and overtide contributions:

$$
\int_{-h}^{\bar{\zeta}} \bar{U}^{S} d z=\overline{\left.U^{\prime}\right|_{\bar{\zeta}} \zeta^{\prime}}+\overline{\left.U^{\prime \prime}\right|_{\bar{\zeta}} \zeta^{\prime \prime}}=\bar{Q}^{S}=\bar{Q}^{S t}+\bar{Q}^{S o}
$$

where an overbar followed by a superscript $S$ indicates a Stokes correction (that is the difference between an Eulerian mean and a mean following a water parcel), and superscripts $S t$ and So indicate Stokes drift terms arising from the tidal and overtide flows, respectively. Along-channel integration of (2a) from arbitrary $x$ to infinity or the head of tide gives, for steady waves, $\int_{-h}^{\bar{\zeta}} \bar{U} d z=-\bar{Q}^{S}-\bar{Q}^{R}$

where $Q^{R}$ is the river flow per unit width. Sediment conservation in two dimensions is given by

$$
\frac{\partial C}{\partial t}=-U \frac{\partial C}{\partial x}-W \frac{\partial C}{\partial z}+\bar{W}_{C} \frac{\partial C}{\partial z}+\frac{\partial}{\partial z} T_{z}
$$

where $T_{z}$ is the vertical turbulent sediment flux. No alongchannel diffusion term is required in $(3 a)$, because horizontal turbulent diffusion is small relative to vertical diffusion and all wave (tidal) fluxes are explicitly included. Vertical and wave cycle integration of ( $3 a)$ gives

$$
\begin{aligned}
& \frac{\partial}{\partial t} \int_{-h}^{\bar{\zeta}} \bar{C} d z=-\frac{\partial}{\partial x} \int_{-h}^{\bar{\zeta}}\left(\overline{U C}+\overline{U^{\prime} C^{\prime}}+\overline{U^{\prime \prime} C^{\prime \prime}}\right) d z \\
& +\left.\left(\overline{-T}_{z}+\bar{W}_{C} \bar{C}\right)\right|_{-h}
\end{aligned}
$$

where a zero net flux boundary condition is assumed at $z=\bar{\zeta}$.

Along-channel integration then provides a preliminary conservation expression. In the case of salt conservation, the along-channel integration was from (arbitrary) $x$ to infinity, because the ocean at $x=0$ was the source of salt and tidal energy so that both salinity and wave velocities die out for large $x$ [Jay, 1991b]. The case of sediment is more complex, because its distribution is not monotonic and because both oceanic and fluvial sources must be considered. The appropriate integration is from $x_{1}$ to $x_{2}$. These limits, while otherwise arbitrary, are assumed to include the ETM. Thus:

$\frac{\partial}{\partial t} \int_{x_{1}}^{x_{2}} \int_{-h}^{\bar{\zeta}} \bar{C} d z d x=\left[\int_{-h}^{\bar{\zeta}}\left(\bar{U} \bar{C}+\overline{U^{\prime} C^{\prime}}+\overline{U^{\prime \prime} C^{\prime \prime}}\right) d z\right] x_{x_{2}}^{x_{2}}+\bar{V}_{f b}$

where the flux at the bed

$$
\bar{V}_{f b}=\left.\int_{x_{2}}^{x_{1}}\left(\overline{-T_{z}}+\bar{W}_{C} \bar{C}\right)\right|_{-h} d x
$$




$$
\bar{U}=<\bar{U}>+\bar{U}_{V} \quad \bar{C}=<\bar{C}>+\bar{C}_{V}
$$

and similarly at tidal and overtide frequencies.

A key intermediate theorem is a generalization of the smallamplitude, steady-wave relationship between wave fluxes of wave frequency scalar variations and Stokes fluxes of the mean field to include vertical mixing. For the tidal frequency wave, GLM theory shows that

$$
\overline{U^{\prime} \cdot \nabla C^{\prime}} \cong \bar{U}^{S t} \cdot \nabla \bar{C}-\overline{\frac{\partial}{\partial z}}_{z}{ }^{S t}-\bar{W}_{C} \frac{\partial \bar{C}}{\partial z}
$$

and similarly for the overtide wave, assuming that $\bar{W}_{C}$ is time and space invariant. The idea behind the Stokes corrections to the mean sediment concentration and mean vertical turbulent flux in (6a) is analogous to the Stokes drift $\bar{U}^{S t}$. In GLM theory, all Eulerian quantities have Stokes corrections that arise as the difference between their Eulerian (at a fixed point) and Lagrangian (following a particle trajectory) means [Andrews and McIntyre, 1978].

The derivation of (6a) is straightforward. One of the consequences of GLM theory is that a time-dependent, Eulerian scalar conservation relationship such as (3a) has a corresponding Lagrangian average (indicated by an overbar followed by a superscript $L$ ) equation following water parcel trajectories [Andrews and McIntyre, 1978, equations (2.20) and (2.21)]; thus in two dimensions ( $x$ and $z$ ),

$$
\frac{\partial \bar{C}^{L}}{\partial t}=-\bar{U}^{L} \frac{\partial \bar{C}^{L}}{\partial x}-\bar{W}^{L} \frac{\partial \bar{C}^{L}}{\partial z}+\bar{W}_{C} \frac{\partial \bar{C}^{L}}{\partial z}+\frac{\bar{\partial}_{\partial z}}{\partial z} T_{z}
$$

The equivalent Eulerian tidal cycle average of ( $3 \mathrm{a}$ ) yields

$$
\begin{gathered}
\frac{\partial \bar{C}}{\partial t}=-\bar{U} \frac{\partial \bar{C}}{\partial x}-\bar{W} \frac{\partial \bar{C}}{\partial z}-\overline{U^{\prime} \frac{\partial C^{\prime}}{\partial x}} \\
-\overline{W^{\prime} \frac{\partial C^{\prime}}{\partial z}}+\bar{W}_{C} \frac{\partial \bar{C}}{\partial z}+\overline{\frac{\partial}{\partial z} T_{z}}
\end{gathered}
$$

Subtraction of (6c) from (6b) yields (6a), after elimination of terms that are negligible for small-amplitude steady waves [Dunkerton 1980 equations (32) to (34)].

Vertical integration of (6a) for a two-dimensional channel flow then yields

$$
\frac{\partial}{\partial x} \int_{-h}^{\zeta} \overline{U^{\prime} C^{\prime}} d z \cong \frac{\partial}{\partial x} \int_{-h}^{\zeta} \overline{U^{S t}} \bar{C} d z
$$

for the tidal frequency wave; an analogous relationship pertains for the overtide wave. The necessary boundary conditions are that wave velocities vanish at the bed and that there is everywhere zero net flux at the mean free surface, that is, that the sum of the vertical settling and vertical turbulent particle flux vanishes at $\bar{\zeta}$ for all $x$ and $t$. Note further that the integration in (6a) and (6d) may also be used on $\mathrm{C}_{\mathrm{V}}$ instead of $C$. Together with the usual rules of averaging deviation quantities, this yields

$$
\left.\left.<\overline{U^{\prime} C_{v}^{\prime}}>=<\overline{U_{v}^{\prime} C_{v}^{\prime}}>=<\bar{U}_{v}^{S t} \bar{C}_{v}\right\rangle=<\bar{U}^{S t} \bar{C}_{v}\right\rangle
$$

Finally, use of (2c), (5), (6d), and (7) in (4a) gives two alternate forms of integral tidal-cycle-averaged sediment conservation:

$$
\begin{aligned}
& \frac{\partial}{\partial t} \int_{x_{1}}^{x_{2}}<\bar{C}>H d x=\left[\overline{-Q}^{R}<\bar{C}>\right. \\
& \left.+\left(<\bar{U}_{v} \bar{C}_{v}>+<\overline{U_{v}^{\prime} C_{v}^{\prime}}><\overline{U_{v}^{\prime \prime} C_{v}^{\prime \prime}}>\right) H\right] \mid \begin{array}{l}
x_{1} \\
x_{2}
\end{array}+\bar{V}_{f b} \\
& =\left[\overline{-Q}{ }^{R}<\bar{C}>+\left(<\bar{U}_{v} \bar{C}_{v}>\right.\right. \\
& \left.\left.+<\left(\bar{U}_{v}^{s t}+\bar{U}_{v}^{s o}\right) \bar{C}_{v}>\right) H\right]\left.\right|_{x_{2}} ^{x_{1}}+\bar{V}_{f b}
\end{aligned}
$$

Both forms of (8) express net transport into and out of a box defined by the bed, mean free surface, and horizontal positions $x_{1}$ and $x_{2}$ in terms of along-channel changes in the shear and stratification between $x_{1}$ and $x_{2}$ and the bed flux $\bar{V}_{f b}$. They differ as to whether the shear and stratification on the right-hand side are expressed in terms of tidal or mean variables. Data analysis has customarily been done with the former; model calculations might be better formulated using the latter. Both forms of (8) contain five terms: a seaward river flow flux, a mean shear transport, tidal and overtide shear transports represented either as tidal or Stokes fluxes, and a flux to or from the seabed. The tidal and overtide frequency motions will be identified with $M_{2}$ and $M_{4}$ herein. Inclusion of additional tidal constituents within each tidal species would add one more term per constituent. Consideration of interactions between neighboring constituents within a tidal species would cause additional terms at tidal monthly frequencies to appear.

The absence of vertically integrated wave flux terms in (8) stems from the fact that landward sediment transport by the vertical integral of the Stokes drift at each wave frequency is exactly counteracted by seaward transport by the vertical integral of the corresponding Eulerian Stokes drift compensation flow to the sea $[(2 c)$ and $(6 d)]$. This also shows why material from a vertically uniform sediment size class (wash load) cannot be trapped: without enough settling to induce stratification of such material, no landward shear flux can occur. The only possibility is uniform seaward transport.

Finally, the shear-sediment stratification correlations in (8) are extremely sensitive to the vertical distributions of $U$ and $C$ at each frequency. Both are strongly dependent on the intensity of vertical turbulent mixing. In many cases the turbulence field will be constrained primarily by the salinity distribution [e.g., Geyer, 1993; Hamblin, 1989]. Some ETM are, however, of sufficient intensity that sediment stratification effects on the velocity profile must also be considered [Gelfenbaum and Smith, 1986].

\section{Results: Analysis of Turbidity Maximum Fluxes}

The mass conservation expression (8) derived in the previous section is sufficiently general to allow analysis of ETM created by a variety of circulation processes, but the discussion in the present section is restricted to ETM created by convergent transport near the upstream limits of salinity intrusion. Specifically, we assume that (1) the time mean position of the ETM is at the tidal average upstream limit of salinity intrusion and (2) processes at locations seaward of mid-ETM occur entirely within the salt water mass, and those on the landward side occur entirely in fresh water. The latter assumption is useful as a conceptual device but represents a simplification of reality, which is complicated by tidal excursions that may be comparable to or larger than the length of the ETM (Figure 1).

\section{Sediment Fluxes in a Steady ETM}

It is a reasonable long-term goal to understand the full timedependent evolution of an ETM under variable tidal and fluvial 
forcing. It is useful, however, and consonant with nonacceleration theorems derived for atmospheric flows (as summarized by Dunkerton, [1980]) to begin interpretation of the sediment balance derived in (8) by analysis of the simplest relevant situation. A steady state in which $\bar{Q}^{R}$ is spatially invariant and tidal-average bed flux $\bar{V}_{f b}$ and the left side of (8) vanish is therefore assumed. This yields

$$
O=\left.\left[-F_{R}+F_{S H}\right]\right|_{x_{1}} ^{x_{2}}=F_{N E T} \mid \begin{aligned}
& x_{2} \\
& x_{1}
\end{aligned}
$$

where $F_{S H}$ is the sum of the shear-stratification correlations at all frequencies, and $F_{R}=\bar{Q}^{R}\langle\bar{C}\rangle$. In this case the net sediment flux $F_{N E T}=F_{S H}-F_{R}$ through $x_{1}$ is the same as that through $x_{2}$. Since $x_{1}$ and $x_{2}$ are arbitrary, $F_{N E T}$ must be spatially uniform for a steady state to pertain (Figure 8). We then choose $x_{1}$ and $x_{2}$ on either side of the ETM such that $<\bar{C}>\left.\right|_{x_{1}}=<\bar{C}>\mid x_{x_{2}}$; then $\left.F_{R}\right|_{x_{1}}=\left.F_{R}\right|_{x_{2}}$ In the simplified, single-size-class situation considered here, the river flow transports exactly as much material out of the ETM at $x_{1}$ as it brings in at $x_{2}$. This emphasizes the indirect role of river flow in creation of an ETM: the river supplies part (usually most) of the material that is concentrated by along-channel gradients in shear fluxes $F_{S H}$. It also supplies the buoyancy flux that sets the stratification and vertical mixing that together determine the shear, but it does not in itself create the ETM through convergent horizontal fluxes.

The along-channel variations in $F_{S H}$ and $F_{R}$ may also be determined (Figure 8). This is possible because we have assumed no erosion or deposition, and thus $F_{N E T}$, the net sediment flux to the sea, is spatially and temporally invariant. Within the ETM the amplitude of seaward fluvial flux $\left.F_{R}=\bar{Q}^{R}<\bar{C}\right\rangle$ is at a maximum because $\bar{Q}^{R}$ is spatially invariant and $\langle\bar{C}\rangle$ is at its highest value. This means that $F_{S H}$ is at a maximum (i.e., relatively more landward) within the ETM. This argument does not alone prove that $F_{S H}$ is positive in sign

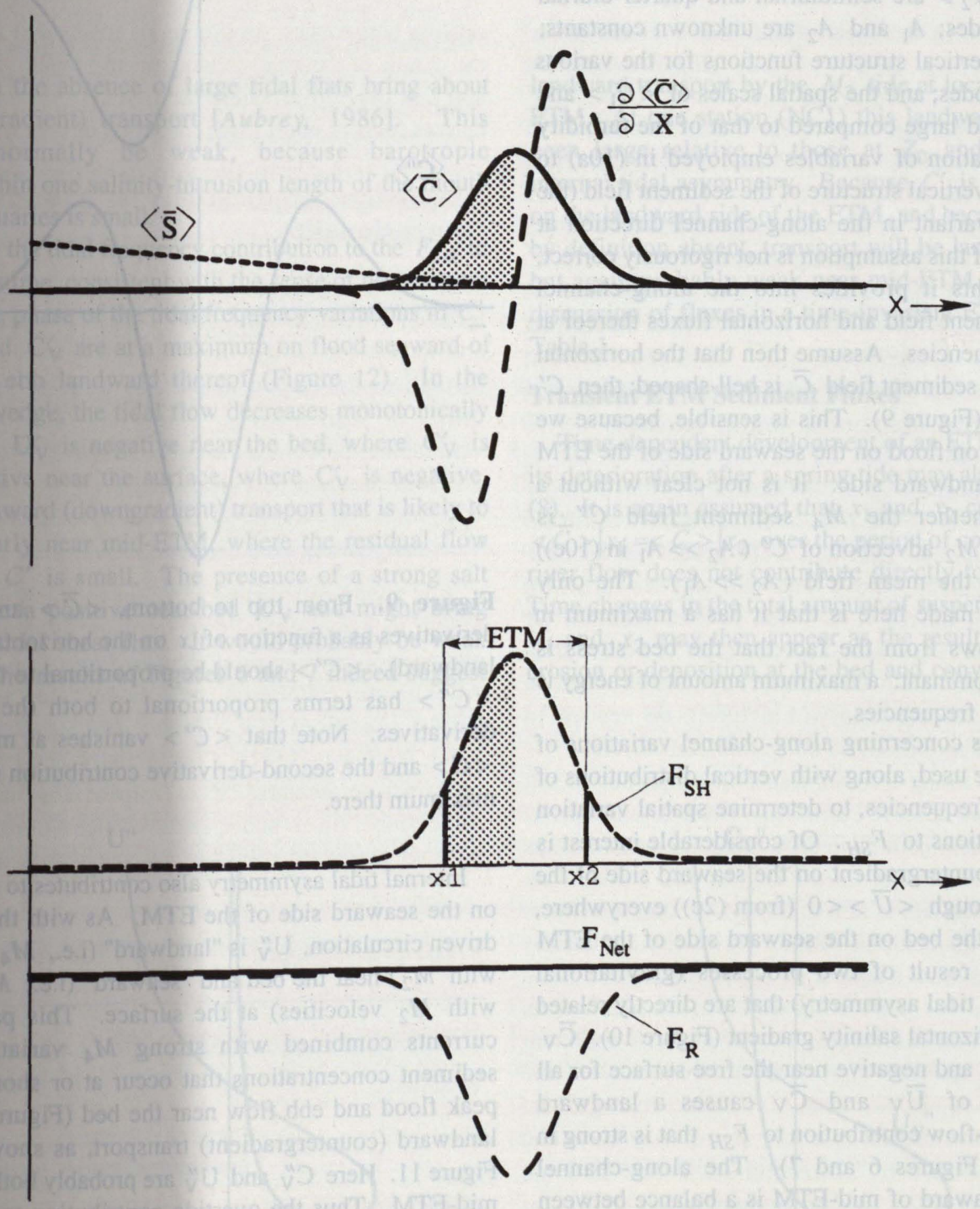

Figure 8. (top) Schematic sketch of vertically integrated salinity (short-dash curve) and sediment distributions (solid curve) and the negative of the along-channel gradient of the sediment distribution (long-dash curve). Positive $x$ is landward and to the right. (bottom) Spatial distributions of total $F_{N E T}$ (solid curve), shear $F_{S H}$ (dashed curve), and fluvial $F_{R}$ (dashed curved) fluxes. The ETM extends approximately from $x_{1}$ to $x_{2}$. Countergradient sediment transport occurs on the seaward side of the ETM (shaded). In the absence of fluxes to and from the bed, $F_{N E T}$ must be spatially uniform for the tidally averaged sediment field to be in a steady state. Both $F_{S H}$ and $F_{R}$ have their maximum amplitudes in the ETM. $F_{S H}$ is landward, and $F_{R}$ is seaward. 
(landward) anywhere; it could be uniformly seaward but less so within the ETM. Consideration in the following paragraphs of the individual contributions to $F_{S H}$ suggests, however, that $F_{S H}$ is in fact positive within the ETM and probably everywhere.

Simple arguments may also be made concerning the alongchannel forms of $C^{\prime}$ and $C^{\prime \prime}$. One foundation of Eulerian wave flux methodology is an assumption that lowest-order wave variations in scalar properties stem from wave advection of the mean field (Middleton and Loder, 1989). This assumption, together with a separation of variables yields:

$$
\begin{aligned}
& \bar{C}(x, z)=M(x) C_{0}(z) \\
& C^{\prime}(x, z, t)=R_{e}\left[\frac{d M}{d x}<U_{1}>C_{1}(z) e^{i t}\right] \\
& C^{\prime \prime}(x, z, t)=R_{e}\left\{\left[A_{1} \frac{d M}{d x}<U_{2}>\right.\right. \\
& \left.\left.+A_{2}<U_{1}>\frac{d}{d x}\left(\frac{d M}{d x}<U_{1}>\right)\right] C_{2}(z) e^{2 i t}\right\}
\end{aligned}
$$

where $\left\langle U_{1}\right\rangle$ and $\left\langle U_{2}\right\rangle$ are semidiurnal and quarter-diurnal tidal transport magnitudes; $A_{1}$ and $A_{2}$ are unknown constants; $C_{0}, C_{1}$, and $C_{2}$ are vertical structure functions for the various suspended sediment modes; and the spatial scales of $\left\langle U_{1}\right\rangle$ and $\left\langle U_{2}\right\rangle$ can be assumed large compared to that of the turbidity maximum. The separation of variables employed in (10a) to (10c) assumes that the vertical structure of the sediment field (the $\left.\mathrm{C}_{\mathrm{i}}(\mathrm{z}), \mathrm{i}=1,3\right)$ is invariant in the along-channel direction at each frequency. Even if this assumption is not rigorously correct, it is useful for insights it provides into the along-channel variability of the sediment field and horizontal fluxes thereof at tidal and overtide frequencies. Assume then that the horizontal part $M(x)$ of the mean sediment field $\bar{C}$ is bell-shaped; then $C^{\prime}$ vanishes at mid-ETM (Figure 9). This is sensible, because we expect $C^{\prime}$ to be larger on flood on the seaward side of the ETM and on ebb and the landward side. It is not clear without a detailed solution whether the $M_{4}$ sediment field $C^{\prime \prime}$ is predominantly due to $M_{2}$ advection of $C^{\prime}\left(A_{2} \gg A_{1}\right.$ in (10c)) or $M_{4}$ advection of the mean field $\left(A_{2} \gg A_{1}\right)$. The only assumption about $C^{\prime \prime}$ made here is that it has a maximum in mid-ETM. This follows from the fact that the bed stress is neither flood nor ebb dominant: a maximum amount of energy is at residual and overtide frequencies.

These considerations concerning along-channel variations of $\bar{C}, C^{\prime}$, and $C^{\prime \prime}$ can be used, along with vertical distributions of $U$ at mean and wave frequencies, to determine spatial variation of the various contributions to $F_{S H}$. Of considerable interest is the fact that $F_{S H}$ is countergradient on the seaward side of the ETM (Figure 8). Although $<\bar{U}><0$ (from (2c)) everywhere, $\overline{\mathrm{U}}_{\mathrm{V}}$ is landward near the bed on the seaward side of the ETM (e.g., at $x=x_{1}$ ) as a result of two processes (gravitational circulation and internal tidal asymmetry) that are directly related to the presence of a horizontal salinity gradient (Figure 10). $\overline{\mathrm{C}}_{\mathrm{V}}$ is positive near the bed and negative near the free surface for all $x$. The correlation of $\overline{\mathrm{U}}_{\mathrm{V}}$ and $\overline{\mathrm{C}}_{\mathrm{V}}$ causes a landward (countergradient) mean-flow contribution to $F_{S H}$ that is strong in many systems (as in Figures 6 and 7). The along-channel distribution of $F_{S H}$ seaward of mid-ETM is a balance between those of $\overline{\mathrm{C}}_{\mathrm{V}}$ (maximum in mid-ETM) and $\overline{\mathrm{U}}_{\mathrm{V}}$, which must decrease sharply at the upstream limit of salinity intrusion. The maximum mean shear flux should then be at or seaward of midETM. On the landward side of the ETM (e.g., at $x=x_{2}$ ), gravitational circulation is symmetry decreases rapidly with increasing $x$, and only a weak landward, downgradient mean shear transport can occur.
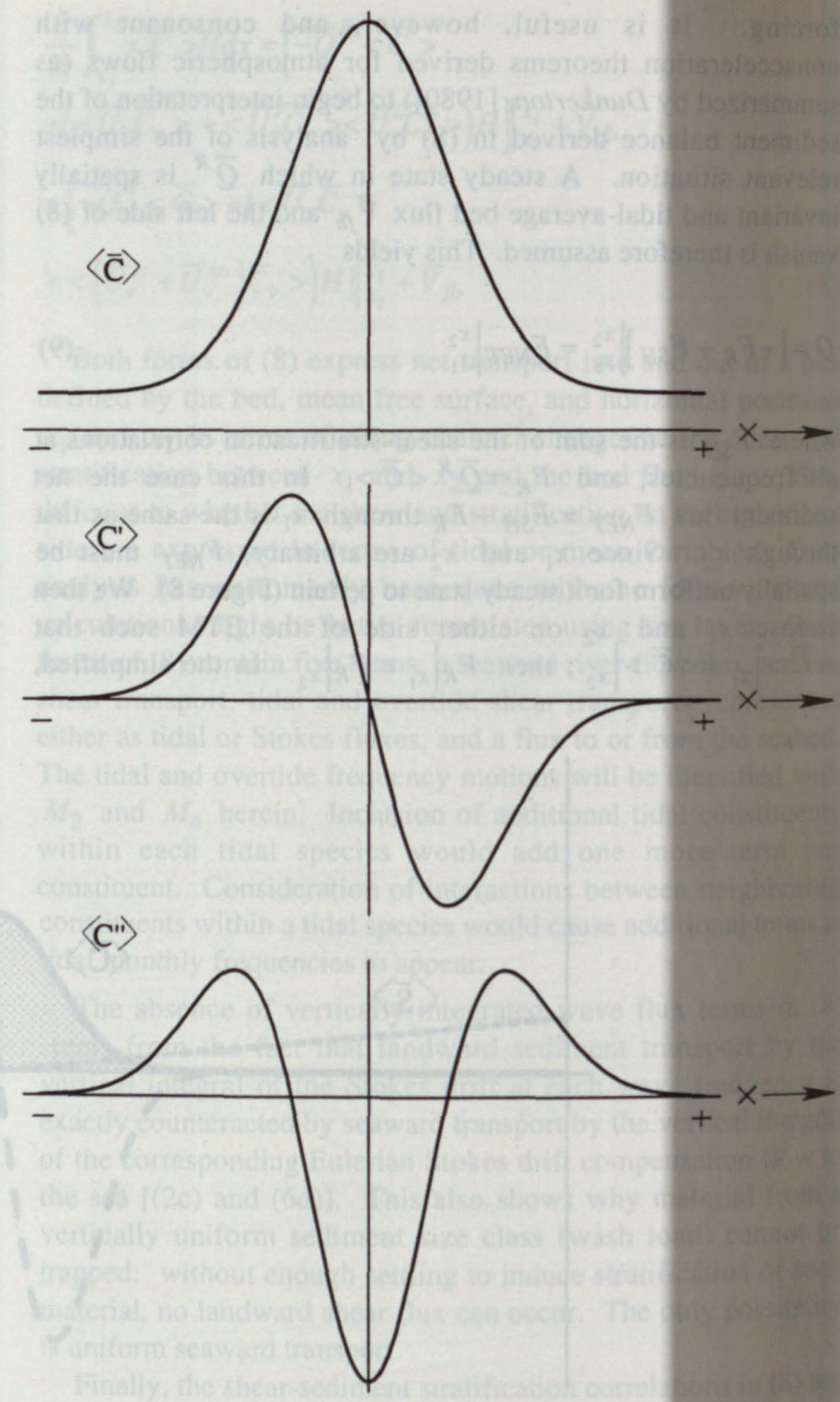

Figure 9. From top to bottom, $\langle\bar{C}\rangle$ and its first two $\mathrm{x}$ derivatives as a function of $x$ on the horizontal axis (positive $x$ landward). $\left\langle C^{\prime}\right\rangle$ should be proportional to the first derivative. $\left\langle C^{\prime \prime}\right\rangle$ has terms proportional to both the first and second derivatives. Note that $\left\langle C^{\prime}\right\rangle$ vanishes at mid-ETM, whereas $<C>$ and the second-derivative contribution to $\left\langle C^{\prime \prime}\right\rangle$ are at a maximum there.

Internal tidal asymmetry also contributes to the $M_{4}$ shear flux on the seaward side of the ETM. As with the steady, densitydriven circulation, $\mathrm{U}_{\mathrm{V}}^{\prime \prime}$ is "landward" (i.e., $M_{4}$ is nearly in phase with $M_{2}$ ) near the bed and "seaward" (i.e., $M_{4}$ is out of phase with $M_{2}$ velocities) at the surface. This pattern of overtide currents combined with strong $M_{4}$ variations in near-bed sediment concentrations that occur at or shortly after times of peak flood and ebb flow near the bed (Figure 3) causes strong landward (countergradient) transport, as shown figuratively in Figure 11 . Here $\mathrm{C}_{\mathrm{V}}^{\prime \prime}$ and $\mathrm{U}_{\mathrm{V}}^{\prime \prime}$ are probably both at a maximum in mid-ETM. Thus the overtide contribution to $F_{S H}$ should also have a maximum in mid-ETM. This is consistent with the observations presented in Figures 6 and 7, which were collected at sites seaward of mid-ETM in the Columbia River estuary. Internal tidal asymmetry must drop rapidly to zero landward from mid-ETM as salinity is present for a smaller and smaller part of the tidal cycle. Finite-amplitude wave steepening and frictional typically shorten and sharpen the flood and lengthen and weaken 

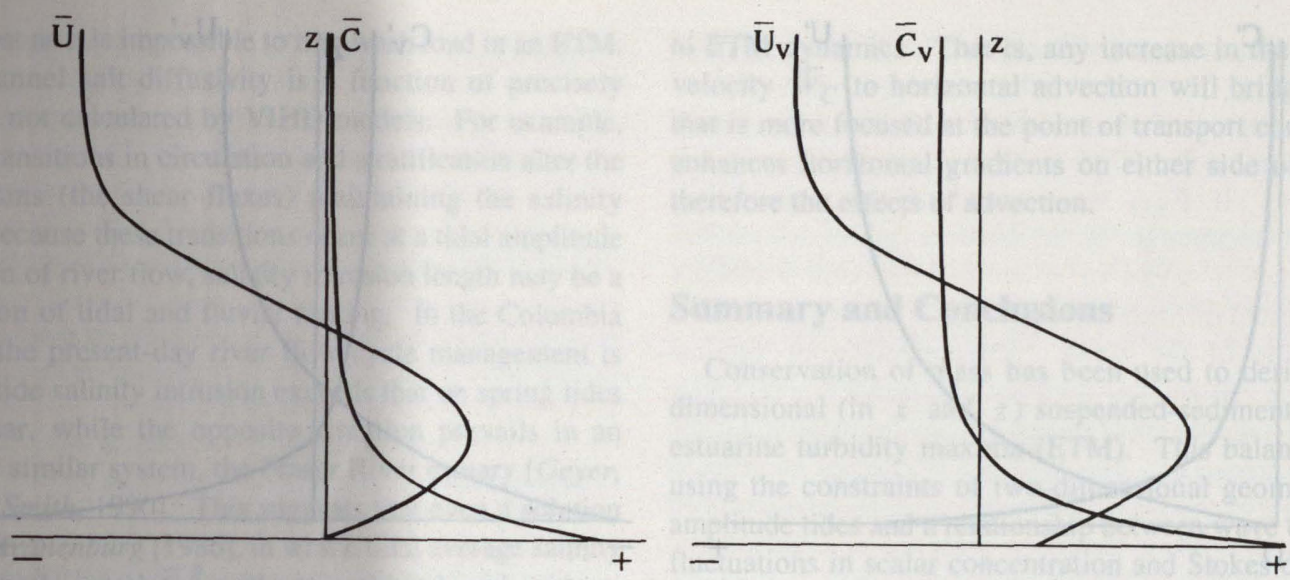

Figure 10. Schematic vertical distribution of mean flow variables (left) $\bar{U}$ and $\bar{C}$ and (right) $\overline{\mathrm{U}}_{\mathrm{V}}$ and $\overline{\mathrm{C}} \mathrm{V}$. $\bar{C}$ increases monotonically with depth, so $\overline{\mathrm{C}}_{\mathrm{V}}>0$ at the bed, as is also true of the sediment stratification at other frequencies. $<\bar{U}><0$ from (2c); this and the change of sign with depth of $\bar{U}$ leads to $\overline{\mathrm{U}}_{\mathrm{V}}>0$ at bed. $\overline{\mathrm{U}}_{\mathrm{V}}$ and $\overline{\mathrm{C}}_{\mathrm{V}}$ are positively correlated.

the ebb, should in the absence of large tidal flats bring about landward (downgradient) transport [Aubrey, 1986]. This transport will normally be weak, because barotropic $M_{4}$ generation within one salinity-intrusion length of the mouth of most narrow estuaries is small.

This leaves only the tidal frequency contribution to the $F_{S H}$ to be considered. Assume, consistent with the sense of near-bottom mean flow, that the phase of the tidal frequency variations in $C^{\prime}$ is such that $C^{\prime}$ and $C_{V}^{\prime}$ are at a maximum on flood seaward of the ETM and on ebb landward thereof (Figure 12). In the absence of a salt wedge, the tidal flow decreases monotonically with depth. Then $\mathrm{U}_{\mathrm{V}}^{\prime}$ is negative near the bed, where $\mathrm{C}_{\mathrm{V}}^{\prime}$ is positive, and positive near the surface, where $\mathrm{C}_{\mathrm{V}}^{\prime}$ is negative, leading to a net seaward (downgradient) transport that is likely to be weak, particularly near mid-ETM, where the residual flow changes sign and $C^{\prime}$ is small. The presence of a strong salt wedge could cause a positive near-bed $\mathrm{U}_{\mathrm{V}}^{\prime}$ and might bring about a landward tidal shear flux. It would probably be weak near mid-ETM. The results of Figures 6 and 7 indeed suggest landward transport by the $M_{2}$ tide at locations seaward of midETM. At one station (NC1) this landward transport may have been large relative to those at $Z_{0}$ and $M_{4}$ associated with internal tidal asymmetry. Because $C^{\prime}$ is at a maximum on ebb on the landward side of the ETM, and because salt wedge flow is by definition absent, transport will be landward (downgradient) but again probably weak near mid-ETM. Results of the above discussion of fluxes in a time-invariant ETM are summarized in Table 1.

\section{Transient ETM Sediment Fluxes}

Time-dependent development of an ETM after a neap tide and its deterioration after a spring tide may also be considered using (8). It is again assumed that $x_{1}$ and $x_{2}$ can be chosen such that $<\bar{C}>\left|x_{1}=<\bar{C}>\right| x_{2}$ over the period of consideration, so that the river flow does not contribute directly to ETM time variation. Time changes in the total amount of suspended sediment between $x_{1}$ and $x_{2}$ may then appear as the result of two processes: net erosion or deposition at the bed and convergence/divergence of
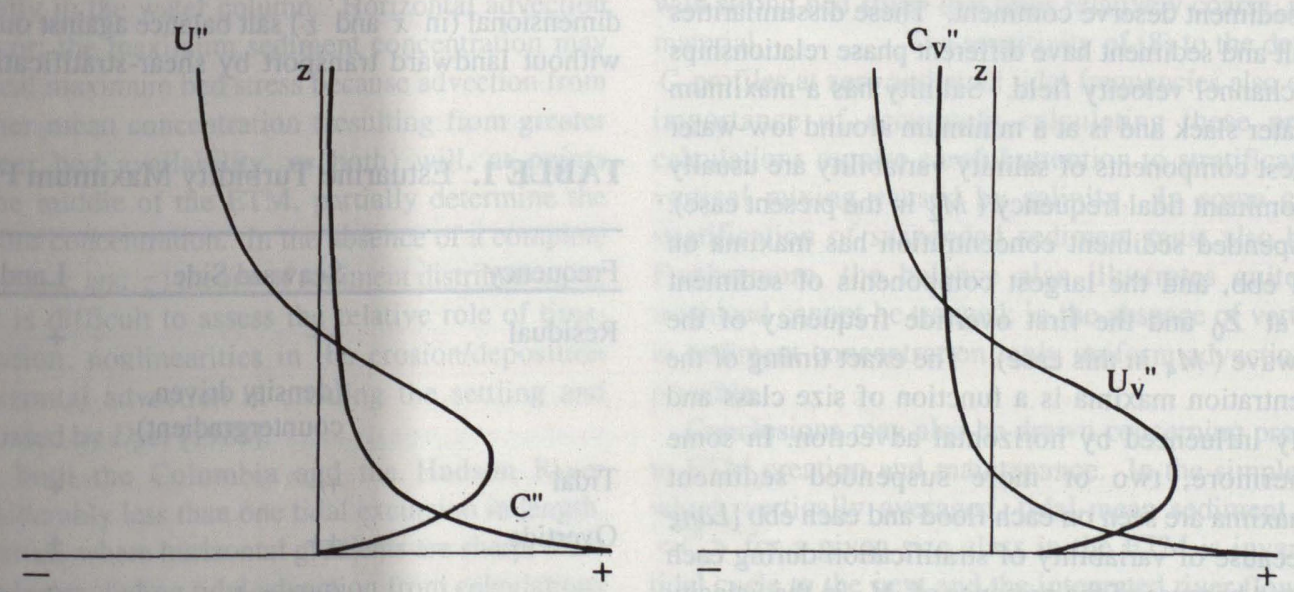

Figure 11. Schematic peak flood vertical distributions of overtide variables (left) $U^{\prime \prime}$ and $C^{\prime \prime}$ and (right) $U_{V}^{\prime \prime}$ and $\mathrm{C}_{\mathrm{V}}^{\prime \prime}$. The spatial distributions of overtide shear and stratification are similar to those at zero frequency. Their phase relationship is such that $\mathrm{U}_{\mathrm{V}}^{\prime \prime}$ and $\mathrm{C}_{\mathrm{V}}^{\prime \prime}$ are positively correlated. In this case, however, $U^{\prime \prime}$ integrates to zero, so that it does not influence the barotropic flow. 

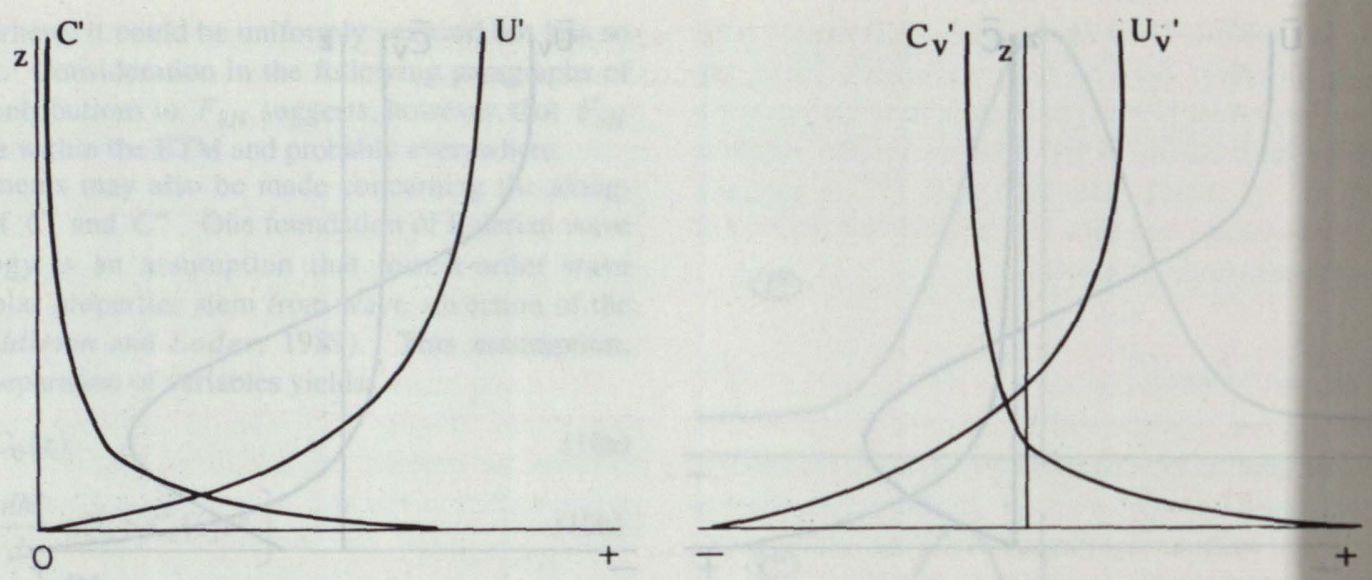

Figure 12. Schematic peak flood vertical distributions of tidal variables (left) $U^{\prime}$ and $C^{\prime}$ and (right) $\mathrm{U}_{\mathrm{V}}^{\prime}$ and $\mathrm{C}_{\mathrm{V}}^{\prime}$. Because $U^{\prime}$ increases monotonically from the bed, $\mathrm{U}_{\mathrm{V}}^{\prime}<0$ at the bed; $\mathrm{U}_{\mathrm{V}}^{\prime}$ and $\mathrm{C}_{\mathrm{V}}^{\prime}$ are thus negatively correlated.

horizontal shear fluxes in the mean, tidal, and overtide flows. After a period of weak tides, an ETM will develop as long as the sum of bed erosion and convergence terms in (8) is positive. Erosion is likely to occur because of increased bed stress. If convergence occurs, it requires transport that is countergradient on the seaward side of the ETM. The ETM will cease to develop when no more net erosion of bed material is possible given ambient shear stresses and/or the along-channel maximum in $\bar{C}$ becomes so pronounced that countergradient transport on the seaward side of the ETM (and thus a convergent horizontal sediment flux) is no longer possible. Conversely, ETM deterioration after a period of strong tides can be expected when the horizontal shear flux becomes divergent (probably downgradient on both sides of the ETM) and/or bed stress is insufficient to keep net deposition from occurring. Tidal monthly variability in the position of the tidal-average salinity intrusion limit may further complicate transient ETM processes, because the entire ETM will typically move landward and seaward with the salinity intrusion, unless it is fixed in one location by topographic influences. Thus time-dependent ETM evolution is inherently more complex than the steady state summarized in Table 1, and model calculations would likely be needed to determine the spatial distributions of the various flux terms.

Finally, the distinct along-channel transport properties of salt and suspended sediment deserve comment. These dissimilarities arise because salt and sediment have different phase relationships with the along-channel velocity field. Salinity has a maximum close to high-water slack and is at a minimum around low-water slack. The largest components of salinity variability are usually at $Z_{0}$ and the dominant tidal frequency ( $M_{2}$ in the present case). In contrast, suspended sediment concentration has maxima on both flood and ebb, and the largest components of sediment variability are at $Z_{0}$ and the first overtide frequency of the dominant tidal wave ( $M_{4}$ in this case). The exact timing of the sediment concentration maxima is a function of size class and may be strongly influenced by horizontal advection. In some systems, furthermore, two or more suspended sediment concentration maxima are seen on each flood and each ebb [Lang et al., 1989], because of variability of stratification during each half tidal cycle and because of the presence of $M_{4}$ in the velocity field. These two factors result in $M_{8}$ variability in the excess shear stress and thus in the suspended sediment field [Jay and Musiak, 1994]. From a wave flux perspective, however, it is the settling and erosion properties of suspended sediment that cause the details of the time-dependent suspended sediment distribution and that thus differentiate the transport behavior of all sediment classes (except wash load) from that of salinity.

\section{Discussion: Implications for Models of Reduced Dimensionality}

Scalar transport problems are often considered in models of reduced dimensionality, both to limit computational complexity and to provide insight into transport processes. The transport formalism developed above has definite implications for the utility of such models. These are developed separately for vertical and horizontal models, because the two approaches have different strengths and weaknesses.

\section{Vertically Integrated Models}

It is a long-established and convenient practice to use a VIHD model to calculate salinity intrusion length and the vertically averaged salinity in tidal channel flows [e.g., Harleman, 1966]. After careful calibration, such models may accurately reproduce known conditions [e.g., Uncles and Stephens, 1990; Robinson. 1983; Holloway, 1981]. Conceptually, however, this procedure is unattractive because it is impossible to maintain a twodimensional (in $x$ and $z$ ) salt balance against outward river flow without landward transport by shear-stratification correlations

TABLE 1. Estuarine Turbidity Maximum Fluxes

\begin{tabular}{lll}
\hline Frequency & Seaward Side & Landward Side \\
\hline Residual & ++ & + \\
& (density driven, & \\
& countergradient) & \\
Tidal & + - & + \\
Overtide & ++ & + \\
& (internal, & (barotropic) \\
\hline
\end{tabular}

Here plus is landward; minus, seaward. 
[Jay, 1991b], just as it is impossible to trap wash load in an ETM. Thus along-channel salt diffusivity is a function of precisely those variables not calculated by VIHD models. For example, tidal monthly transitions in circulation and stratification alter the basic mechanisms (the shear fluxes) maintaining the salinity intrusion, and because these transitions occur at a tidal amplitude that is a function of river flow, salinity intrusion length may be a complex function of tidal and fluvial forcing. In the Columbia River estuary, the present-day river flow cycle management is such that neap-tide salinity intrusion exceeds that on spring tides most of the year, while the opposite situation prevails in an apparently very similar system, the Fraser River estuary [Geyer, 1988; Jay and Smith, 1990]. This suggests that even a solution such as that of Kranenburg [1986], in which tidal average salinity is a function of both $x$ and $\bar{Q}^{R}$, will not in general work without a great deal of tuning. VIHD models are thus limited as predictive tools, even for salinity.

Vertically integrated models in one or two horizontal dimensions are poorly suited to description of the suspended sediment field and its transport, because each size class of sediment will have distinct transport characteristics and because apparently countergradient transport will occur in the vicinity of maxima in the longitudinal distribution. Horizontal sediment diffusivities in such a model must either be tuned empirically for each size class or be determined from the distribution of some other scalar such as salinity. The former will lead to negative diffusivities in the circumstances defined in previous sections and limits the role of such a model essentially to interpolation of observations. The latter necessarily leads to incorrect representation of wave flux transports of sediment.

\section{One-Dimensional Vertical Models}

Most calculations of suspended sediment profiles, whether steady or time-dependent, have assumed horizontal uniformity, so horizontal divergence effects could be neglected. Although the above analysis has not investigated the details of the vertical distributions of sediment at the various wave frequencies, it has emphasized that ETM dynamics must be viewed as a balance between local vertical processes and horizontal advection. Including local acceleration effects in calculations of sediment profile creates a phase shift between maximum bed stress and peak sediment concentration at points removed from the bed [Smith, 1977]. This lag represents the time required for sediment to diffuse vertically in the water column. Horizontal advection adds another factor; the maximum sediment concentration may lead or lag the local maximum bed stress because advection from locations of higher mean concentration (resulting from greater bed stress, greater bed availability, or both) will, at points removed from the middle of the ETM, partially determine the timing of maximum concentration. In the absence of a complete two-dimensional (in $x$ and $z$ ) theory of sediment distribution for tidal channels, it is difficult to assess the relative role of timevarying stratification, nonlinearities in the erosion/deposition process and horizontal advection in creating the settling and erosion lags discussed by Dyer [1988].

The ETM in both the Columbia and the Hudson River estuaries are considerably less than one tidal excursion in length. In such river estuaries, where horizontal gradients are sharp, there is no justification for excluding tidal advection from calculations of suspended-sediment profiles. It can further be predicted that the larger $\bar{W}_{C}$ is for the sediment trapped in the ETM (i.e., the larger the prevailing bed stress), the more important advection is to ETM dynamics. That is, any increase in the ratio of settling velocity $\bar{W}_{C}$ to horizontal advection will bring about an ETM that is more focused at the point of transport convergence. This enhances horizontal gradients on either side of mid-ETM and therefore the effects of advection.

\section{Summary and Conclusions}

Conservation of mass has been used to derive a new, twodimensional (in $x$ and $z$ ) suspended-sediment balance (8) for estuarine turbidity maxima (ETM). This balance is simplified using the constraints of two-dimensional geometry and smallamplitude tides and a relationship between wave transport of tidal fluctuations in scalar concentration and Stokes drift transport of the mean scalar field. The resulting balance shows that time changes in tidal-mean sediment size-class concentration between two estuarine cross sections are caused by the sum of seaward river flow transport, landward transport associated with correlations between shear and stratification in the mean flow and at the various tidal frequencies, and fluxes to and from the bed. Vertically integrated wave modes (e.g., correlations of vertical averages $\left\langle U^{\prime}\right\rangle$ and $\left\langle C^{\prime}\right\rangle$ of along-channel tidal velocity $U^{\prime}$ and sediment concentration $C^{\prime}$ ) cannot transport material landward, because this landward transport is exactly counteracted by seaward transport associated with the Eulerian residual excited by the landward Stokes drift.

This balance emphasizes the joint role of horizontal advection and vertical processes (settling, deposition, vertical mixing, and erosion) in determining suspended sediment distributions in estuarine systems. Thus appearance of an ETM at a given location does not necessarily indicate a local maximum in resuspension at that location. It represents instead a balance between local resuspension and convergent horizontal advection. If in fact there is a resuspension maximum in mid-ETM, this strong local resuspension likely reflects convergent transport at some earlier time, either during a tidal month or a season. Advection from a location of greater bed concentration provides, furthermore, another explanation (in addition to nonlinearities in erosion/deposition at the sea bed, acceleration, and time-varying stratification) of why peak sediment concentration does not occur at the time of peak bed stress. The importance of advection varies directly with the settling velocity of material trapped in the ETM. Thus advection is likely to be most important in systems with strong bed stress that traps relatively coarse, rapidly settling material. The sensitivity of (8) to the details of $U$ and $C$ profiles at zero and at all tidal frequencies also emphasizes the importance of accurately calculating these profiles. Such calculations require careful attention to stratification effects on vertical mixing caused by salinity. In some cases the selfstratification of suspended sediment must also be considered. Furthermore, the balance also illustrates quite simply why washload cannot be trapped: in the absence of vertical variations in sediment concentration, only uniform advection to the sea is possible.

Conclusions may also be drawn concerning processes leading to ETM creation and maintenance. In the simplest situation in which vertically averaged, tidal-mean sediment concentration $<\bar{C}>$ for a given size class in the ETM is invariant from one tidal cycle to the next and the integrated river flow $\bar{Q}_{R}$ is steady and uniform in the along-channel direction, the local maximum of $\langle\bar{C}\rangle$ in the ETM causes a local maximum in the seaward transport by the river flow $F_{R}=-\bar{Q}_{R}<\bar{C}>$. Because a steady 
state situation implies a spatially and temporally constant net sediment flux $F_{N E T}$ toward the sea, landward transport of sediment by the various shear-stratification modes $\left(F_{S H}\right)$ must be at a maximum in the ETM so that $F_{N E T}=-F_{R}+F_{S H}$ is spatially uniform. If $F_{N E T}$ were not spatially invariant, then sediment would accumulate or be removed at some location. When represented in terms of a one-dimensional, vertically integrated horizontal diffusion model, $F_{S H}$ is countergradient on the seaward side of the ETM. Consideration of vertical distribution of the various flow modes suggests that it is primarily the residual and overtide shear fluxes that are responsible for the countergradient transport. The presence of diurnal currents in West Coast estuaries may also, however, through quadratic bed stress nonlinearities, bring about the presence of a substantial semidiurnal contribution to ETM sediment fluxes.

It is also important to relate the present analysis to the idea advanced by Hamblin [1989] and Geyer [1993] that inhibition of vertical mixing by density stratification contributes to near-bed variations in suspended sediment concentration in a way that is likely to be correlated with tidal advection. In the context of the present analysis, the suppression of upward mixing of sediment by density stratification serves to trap sediment near the bed on the seaward side of the ETM, where it may be moved landward by gravitational circulation and/or internal tidal asymmetry. Geyer is correct in pointing out that convergent two-layer mean flow has been emphasized (and possibly overemphasized) in earlier studies as the primary trapping agent. The present analysis shows, moreover, that density stratification may enhance particle trapping through its influence on the vertical distributions of both suspended-sediment and velocity at a variety of frequencies, because it is correlations between velocity shear and suspended-sediment stratification at residual and various tidal frequencies that traps particles. To take these arguments one step further: the effect of tidally varying vertical scalar mixing may drive overtide and residual variations in particle concentration through the vertical turbulent flux term in the sediment conservation equation. The mechanism is exactly analogous to the time-varying vertical momentum flux that gives rise to internal tidal asymmetry in the along-channel flow field.

The present analysis also has interesting implications for box and other vertically integrated horizontal diffusion models. The absence of $\langle U\rangle$ and $\langle C\rangle$ from the integral balance (except in $F_{R}$ ) shows that the channel flow transport scalar is inherently two-dimensional and can be reduced to a one-dimensional diffusion problem only under special circumstances. Mean and overtide sediment transports on the seaward side of the ETM are countergradient (for a steady state and in terms of the vertically integrated sediment concentration), even though salt transport is downgradient at the same location. Landward transport occurs for both salt and sediment, because both are concentrated near the bed, where transport is landward. That a vertically integrated horizontal diffusion model can often be made to describe an along-channel scalar distribution is convenient, but it is not a reflection of fundamental physics. Thus vertically integrated horizontal diffusion models should be applied with care to stratified tidal channel flows.

The different along-channel transport properties of salt and suspended sediment arise out of the details of their respective relationships to the tide and overtide velocity fields. Salinity is high at the end of flood and low at the end of ebb. Suspended sediment concentration usually has maxima on both flood and ebb in response to flood and ebb maxima in bed stress. More fundamentally, the suspended sediment and salinity fields behave differently because settling and deposition/erosion additional degrees of freedom into the sediment balance variations in sediment concentration are not exclusively of wave advection of a mean field.

Acknowledgments. This work has been supported by OCE-8711790 (physical oceanography) and OCE-8918193, th River Estuary Land Margin Ecosystem Research Program. Diana Blumberg for assistance in text formatting and Lyn Sy drafting. Nancy Kachel and an anonymous reviewer provided helpful comments on the manuscript.

\section{References}

Allen, G. P., J. C. Salomon, P. Bassoullet, Y. Du Penhoat, and Grandpre', Effects of tides on mixing and suspended sedime macrotidal estuaries, Sediment. Geol. 26, 69-80, 1980.

Andrews, D. G., and M. E. McIntyre, Planetary waves in horiz vertical shear: The generalized Eliassen-Palm relation and $\mathrm{r}$ acceleration, J. Atmos. Sci., 33, 2031-2048, 1976.

Andrews, D. G., and M. E. McIntyre, An exact theory of nonli on a Lagrangian-mean flow, J. Fluid Mech., 89, 609-646, 1

Aubrey, D. G., hydrodynamic controls on sediment transport in mixed bays and estuaries, in Physics of Shallow Estuaries a edited by J. van de Kreeke, Coastal Estuarine Stud., vol. 16 258, AGU, Washington, D. C., 1986.

Dunkerton, T., A Lagrangian mean theory of wave, mean-flow with applications to non-acceleration and its breakdown, $R e$ Geophys., 18, 387-400, 1980.

Dyer, K. R., Estuaries: A Physical Introduction, pp. 64-70, J. York, 1973.

Dyer, K. R., The balance of suspended sediment in the Girond Thames Estuaries, in Estuarine Transport Processes, edited Kjerfve, University of South Carolina Press, Columbia, pp. 1978.

Dyer, K. R., Fine sediment transport in estuaries, in Physical $P$ Estuaries, edited by J. Dronkers and W. van Leussen, pp. 2 Springer-Verlag, New York, 1988.

Dyer, K., and E. M. Evans, Dynamics of turbidity maximum in homogeneous tidal channel, J. Coastal. Res., 5, special issue, 1989.

Festa, J. F., and D. V. Hansen, Turbidity maxima in partially $m$ estuaries --a two-dimensional numerical model, Estuarine Shelf Sci., 7, 347-359, 1978.

Fischer, H. B., Mass transport mechanisms in partially mixed e Fluid Mech., 53, 671-687, 1972.

Gelfenbaum, G., and J. D. Smith, Experimental evaluation of generalized suspended-sediment transport theory, in Shelf Sandstones, edited by R. J. Knight and J. R. McLean, Can. Geol. Mem., 2, 133-144, 1986.

Geyer, W. R., The advance of a salt wedge front: Observations dynamical model, in Physical Processes in Estuaries, edited Dronkers and W. van Leussen, pp. 181-195, Springer-Verla York, 1988.

Geyer, W. R., The importance of suppression of turbulence by stratification on the estuarine turbidity maximum, Estuaries $125,1993$.

Glenn, S. M., and W. D. Grant, A suspended sediment stratific correction for combined wave and current flows, J. Geophy 469-481, 1987.

Hamblin, P. F., Observations and model of sediment transport turbidity maximum of the upper Saint Lawrence Estuary, J. Res., 94, 14,419-14,428, 1989.

Hansen, D. V., Salt balance and circulation in partially mixed $e$ Estuaries, Publ. 83, pp. 45-51, Am. Assoc. for the Adv. of Washington, D. C., 1965

Harleman, D. R. F., Diffusion processes in stratified flows, in $E$ and Coastal Hydrodynamics, edited by A. T. Ippen, pp. 575 McGraw-Hill, New York, 1966. 
Holloway, P. E., Longitudinal mixing in the upper reaches of the Bay of Fundy, Estuarine Coastal Shelf Sci., 13, 495-515, 1981.

Hughes, F. W., and M. Rattray Jr., Salt flux and mixing in the Columbia River Estuary, Estuarine Coastal Shelf Sci., 10, 479-493, 1980.

Ianniello, J. P., Tidally-induced residual circulation in estuaries of variable width and depth, J. Phys. Oceanogr., 9, 962-974, 1979.

Jay, D. A., Internal asymmetry and anharmonicity in estuarine flows, in Progress in Tidal Hydrodynamics, edited by B. B. Parker, pp. 521546, Wylie-Interscience, New York, 1991a.

Jay, D. A., Estuarine salt conservation: a Lagrangian approach, Estuarine Coastal Shelf Sci., 32, 547-565, $1991 \mathrm{~b}$.

Jay, D. A., and J. D. Musiak, Internal overtide generation in tidal channel flows: Origins and consequences, Physics of Estuaries and Coastal Seas, Coastal Estuarine Stud., edited by C. Pattiaratchi, AGU, Washington, D. C., in press 1994.

Jay, D. A., and J. D. Smith, Residual circulation in and classification of shallow, stratified estuaries, in Physical Processes in Estuaries, edited by J. Dronkers and W. van Leussen, pp. 21-41, Springer-Verlag, New York, 1988.

Jay, D. A., and J. D. Smith, Circulation, density distribution and neapspring transitions in the Columbia River Estuary, Prog. Oceanogr., 25, 81-112, 1990.

Kachel, N., and J. D. Smith, Sediment transport and deposition on the Washington continental shelf, in Coastal Oceanography of Washington and Oregon, edited by M. R. Landry and B. M. Hickey, pp. 287-348, Elsevier, Amsterdam, 1989.

Kineke, G. C., and R. W. Sternberg, The effect of particle settling on computed suspended sediment profiles, J. Mar. Geol., 90159-174, 1989.

Kranck, K., and T. G. Milligan, Characteristics of suspended particles at an 11-hour anchor station in San Francisco Bay, J. Geophys. Res., 97, $11,373-11,382,1992$.

Kranenburg, C., A time scale for long-term salt intrusion in well-mixed estuaries, J. Phys. Oceanogr., 16, 1329-1331, 1986.

Krone, R. B., A field survey of flocculation as a factor in estuarial shoaling processes, Tech. Bull. 19, 62 pp., Comm. on Tidal Hydraul., U.S. Army Corps of Eng., Vicksburg, Miss., 1972.

Lang, G., R. Schubert, M. Markovsky, H.-U. Fanger, I. Grabbeman, H. L. Kraseman, L. J. R. Neumann, and R.. Riethmuller, Data interpretation and numerical modelling of mud and suspended sediment transport experiment 1985, J. Geophys. Res, 94,14,381-14,394, 1989.

Lewis, P. E., and J. O. Lewis, The principal factors contributing to the flux of salt in a narrow, partially stratified estuary, Estuarine Coastal Shelf Sci., 16, 599-626, 1983.

Meade, R. H., Transport and deposition of sediments in estuaries, Mem. Geol. Soc. Am., 133, 91-120, 1972.
Middleton, J. F., and J. W. Loder, Skew fluxes in polarized wave fields, J. Phys. Oceanogr., 19, 68-76, 1989.

Nichols, M., and G. Poor, Sediment transport in a coastal plain estuary, $J$. Waterw. Harbors Coastal. Eng. Div. Am. Soc. Civ. Eng., 93, 83-95, 1967.

Postma, H., Transport and accumulation of suspended matter in the Dutch Wadden Sea, Neth. J. Sea Res., 1, 148-190, 1961.

Robe, R. Q., Salt flux in and classification of the Columbia River Estuary during high and low discharge, M.S. thesis, Univ. of Wash., Seattle, 1968.

Robinson, I. S., A tidal flushing model of the Fleet I(em an English tidal lagoon, Estuarine Coastal Shelf Sci., 16, 669-688, 1983.

Smith, J. D., Modelling sediment transport on continental shelves, in The Sea, vol. 6, edited by E. D. Goldberg, pp. 539-572, John Wiley, New York, 1977.

Uncles, R. J., R. C. A. Elliot, and S. A. Weston, Dispersion of salt and sediment in a partially mixed estuary, Estuaries, 8, 256-269, 1985.

Uncles, R. J., and J. A. Stephens, Computed and observed currents, elevations, and salinity in a branching estuary, Estuaries, 13, 133-144, 1990.

van Leussen, W., Aggregation of particles, settling velocity of mud flocs: A review, in Physical Processes in Estuaries, edited by J. Dronkers and W. van Leussen, pp. 347-403, Springer-Verlag, New York, 1988.

Weir, D. J., and J. McManus, The role of wind in generating turbidity maxima in the Tay Estuary, Cont. Shelf Res., 7, 1315-1318, 1987.

West, J. R., D. W. Knight, and K. Shiono, A note on flow structure in the Great Ouse estuary, Estuarine Coastal Shelf Sci., 19, 271-290, 1985.

West, J. R., R. J. Uncles, J. A. Stephens, and K. Shiono, Longitudinal dispersion processes in the upper Tamar Estuary, Estuaries, 13,118$124,1990$.

Winterwerp, J. C., Decomposition of the mass transport in narrow estuaries, Estuarine Coastal Shelf Sci., 16, 627-638, 1983.

Zhou, M., Internal circulation and salt intrusion in the Hudson Estuary, Ph.D. thesis, State University of New York at Stony Brook, 1992.

Zimmerman, J. T. F., On the Euler-Lagrange transformation and the Stokes drift in the presence of oscillatory and residual currents, J. Mar. Res., 38, 601-630, 1980.

D. A. Jay and J. D. Musiak, Graduate Program in Geophysics, AK-50, University of Washington, Seattle, WA 98195.

(Received January 29, 1993; revised January 11, 1994; accepted February 1, 1994.) 